\title{
Supramolecular assembly based on "emerging" intermolecular interactions of particular interest to coordination chemists
}

\author{
Edward R.T. Tiekink*
}

Research Centre for Crystalline Materials, Faculty of Science and Technology, Sunway University, No. 5 Jalan Universiti, 47500 Bandar Sunway, Selangor Darul Ehsan, Malaysia

* Corresponding author. +60 374917173. Fax: +60 374918633.

E-mail address: edwardt@ sunway.edu.my (E.R.T. Tiekink)

\section{Contents}

1. Introduction

2. Secondary bonding interactions

\subsection{Overview}

2.2 Examples of tetrel, pnictogen and chalcogen secondary bonding

2.3 Steric effects and secondary bonding

3. Metal $\cdots$ metal interactions in supramolecular chemistry

3.1 Overview

3.2 Aurophilic $(\mathrm{Au} \cdots \mathrm{Au})$ interactions

3.3 Metallophilic $\left(\mathrm{M}^{\cdots} \mathrm{M}\right)$ interactions

3.4 Heterometallophilic ( $\left.{ }^{\cdots} \cdots M^{\prime}\right)$ interactions

4. Metal $\cdots$ hydrogen interactions as supramolecular synthons 
5. Metal $\cdots \pi$ (arene) interactions

\section{$5.1 \quad$ Preamble}

5.2 Metal $\cdots \pi($ arene) interactions

5.3 Metal(lone-pair) $\cdots \pi($ arene) interactions

6. Interactions involving chelate rings

7. Interactions involving quasi-chelate rings

8. Conclusions 


\begin{abstract}
An overview of supramolecular assembly sustained by intermolecular contacts pertinent to the coordination chemistry community is presented. Herein, the supramolecular architectures sustained by secondary bonding, encompassing tetrel, pnictogen and chalcogen bonding, interactions occurring between metal centres, metal ${ }^{\cdots}$ hydrogen, metal $\cdots \pi$, main group element(lone pair) $\cdots \pi$, and finally, those involving chelate rings sustained by formal bonding or by hydrogen bonding are described. Whenever possible, comments are included on the nature of the intermolecular interactions and information on the energy of stabilisation they impart. A wide range of intermolecular connectivities are applicable to heavy element compounds and these complement the more established hydrogen bonding and halogen bonding. Interestingly, the energies associated with "emerging" intermolecular interactions often approach those of conventional intermolecular interactions suggesting these may be competitive in directing the way molecules assemble in the condensed phase.
\end{abstract}

Keywords: Coordination chemistry; supramolecular chemistry; self-assembly; crystal engineering 


\section{Introduction}

Since being mooted over 25 years ago by Hoskins and Robson [1], without a doubt research encompassing coordination frameworks/coordination polymers/metal-organic frameworks has resulted in a remarkable resurgence of interest in coordination chemistry. In this endeavour, metal centres, be they transition metals, main group elements or even lanthanides and actinides, are linked via bridging ligands, both charged, e.g. multi-functional carboxylates, and neutral, e.g. suitably spaced bipyridyl-type molecules, into one-, two- and three-dimensional frameworks. The diversity of structural motifs/supramolecular topologies is vast owing the incredible range of possible combinations of metal centres, with different coordination preferences, oxidation states, etc., and organic linkers, neutral or charged, various donor atoms, dentiticity, etc., let alone the dependence of products on synthetic procedures, temperature, solvent, concentration, time, etc. [2]. While the topic has been well-reviewed over the years [3], the enormous diversity of applications now leads to reviews on specific applications/classes of applications. Without discounting the aesthetic appeal of their structures, the motivations for their study is widely driven by applications with relevance to materials chemistry [4] and biological considerations [5]. As gleaned from the very recent literature, applications in materials science span an incredibly diverse range from gas adsorption, sensing and separation [6a-d], photo-responsive materials [6e-g], non-linear optics [6h], charge-transport materials [6i], energy storage [6j], high-energy materials [6k], encapsulation of nanomaterials [61-n], bioremediation [6o,p] and as catalysts [6q,r]. In terms of biological uses, metal-organic frameworks find applications as potential drug delivery vehicles [7a], therapeutic agents [7b], enzyme mimics [7c], substrates for immobilisation [7d] and contrast agents for imaging [7e]. Recently, the idea of incorporating/docking small organic molecules in metal-organic frameworks for structure determination by X-ray crystallography for otherwise intractable materials, i.e. exploiting the idea of "crystalline sponges" was 
described [8]. It seems that these advances, an obvious triumph of molecular solid-state chemistry/crystal engineering endeavours, are limited only by the imagination of the practitioner. The boundless opportunities for the coordination chemist/crystal engineer notwithstanding, the generation of these materials is still only one of many aspects of crystal engineering.

There is a wide consensus that there are three paradigms in crystal engineering, proffered by Desiraju [9], and these, simply stated, are to understand intermolecular forces, i.e. the way molecules self-assemble, to use this knowledge for the rational design of new materials and then to tailor/optimise these for specific applications. With the foregoing in mind, threedimensional crystalline materials are readily rationalised in terms of the various linkers between metal centres but, what of two- and one-dimensional frameworks - how are they assembled? and, what about zero-dimensional species? While it is well established that lowerdimensional frameworks can be assembled into three-dimensional architectures by the strong and directional forces afforded by hydrogen bonding and by halogen bonding [10], herein, an overview of non-conventional intermolecular interactions with specific relevance to coordination chemistry is undertaken.

The identification of points of contact between molecules is a key element of crystal engineering and underscores the widely popular supramolecular synthon approach in crystallography [11]. Repeat patterns identified from a collection of crystal structures might be exploited to deliberately arrange molecules in designed crystal structures, i.e. can be exploited to be structure directing by arranging molecules, de novo, in a controlled manner. However, a fundamental question confronts the crystal engineering community when evaluating specific intermolecular interactions. Phrased simply: are the identified intermolecular interactions indeed structure directing, i.e. do they determine the way molecules self-assemble or, rather, do these intermolecular interactions eventuate as a consequence of 
global crystal considerations? [12]. This question must be posed as an individual, conventional hydrogen bond formed between a pair of molecules is inherently weak, at best, an order of magnitude less than a comparable covalent interaction and the electrostatic potential between constituent molecules. This is underscored by the observations from computational chemistry that crystal packing arrangements for molecules, i.e. polymorphs, differ in energy by $<2-3$ $\mathrm{kcal} / \mathrm{mol}$ [13], at least in organic systems. While this question of how crystals are formed is beyond the scope of this review, it is salient to keep in mind when contemplating the significance of supramolecular assembly sustained by inherently weak interactions. The other point that needs to be highlighted is that just as covalent bonds are not usually formed in isolation, intermolecular interactions are often acting in concert with other supporting interactions, i.e. are acting cooperatively [14].

Herein, a survey of "emerging" intermolecular interactions pertinent to the coordination chemistry community is presented. After an overview of the now well-documented secondary bonding and metal $\cdots$ metal interactions, interactions directly involving metal centres, i.e. $\mathrm{M} \cdots \mathrm{H}$, $\mathrm{M}^{\cdots} \pi$ and $\mathrm{M}$ (lone-pair) $\cdots \pi$, are summarised. Then, attention is directed to the participation of chelate rings in supramolecular associations, i.e. in $\pi$ (chelate) ${ }^{\cdots} \pi$ and $\pi$ (chelate) ${ }^{\cdots} \pi$ (chelate) interactions as well as acceptors in $\mathrm{C}-\mathrm{H}^{\cdots} \pi$ (chelate) interactions. This implies that three key modes of supramolecular association are excluded from this survey, namely hydrogen bonding [15], halogen bonding [16] and formal anion/cation $\cdots \pi$ [17] interactions as there are ample authoritative reviews available for these topics. The present survey is not meant to be exhaustive but, rather is designed to highlight intermolecular interactions that are being revealed as important in the self-assembly of heavy-element compounds in their crystal structures. In short, the emphasis is upon highlighting selected supramolecular associations based on the specific contact under scrutiny as well as any insight into the nature and energy of the interaction as revealed by computational chemistry, and is meant to complement earlier 
reviews of inorganic crystal engineering [18]. Diagrams are original and are drawn with DIAMOND [19a] using crystallographic data extracted from the Cambridge Structural Database (CSD) [19b] and with data interrogation relying heavily on PLATON [19c].

\section{Secondary bonding interactions}

\subsection{Overview}

Secondary bonding, alternatively termed as soft-soft, closed-shell, non-bonding or semi-bonding interactions, are well known to coordination chemists, especially those working with heavier main group elements [20]. Such interactions typically form between a metal centre, the Lewis acid (A), and an electron-rich donor, the Lewis base (X), i.e. $\mathrm{X}-\mathrm{A}^{\cdots} \mathrm{X}^{\prime}$, with the strength of the interaction increasing with the size of A, correlating with increased polarisability. Secondary interactions lead to easily recognisable supramolecular architectures as they often play a crucial structure-directing role in assembling molecules. As for other interactions discussed in this overview, experimental evidence for secondary bonds is readily gleaned from geometric data gained from X-ray structure determination in that the $A^{\cdots} X^{\prime}$ separation falls between the A-X covalent bond length on the one hand and the sum of the van der Waals radii of A and $X^{\prime}$ on the other. The presence of $\mathrm{A}^{\cdots} \mathrm{X}^{\prime}$ ' secondary interactions usually results in an elongation of the $\mathrm{A}-\mathrm{X}$ bond length owing to the redistribution of electron density. The $\mathrm{X}-\mathrm{A}^{\cdots} \mathrm{X}^{\prime}$ interactions are more often than not, linear or close to linear, and usually cause significant disruption to the immediate coordination geometry about the A atom participating in such an interaction.

From a bonding perspective, traditionally, the nature of an $\mathrm{A}^{\cdots} \mathrm{X}^{\prime}$ secondary interaction has been accepted as being based on charge-transfer, i.e. the donation of a lone-pair of electrons on $\mathrm{X}^{\prime}$ into a $\sigma^{*}$-orbital of the $\mathrm{A}-\mathrm{X}$ bond. An equivalent description is based on an asymmetric four-electron, three-centre arrangement whereby $\sigma$-orbitals of each of $\mathrm{A}, \mathrm{X}$ and $\mathrm{X}$ ' combine to 
form three molecular orbitals (MO): a fully occupied MO localised between A and X, a fully occupied MO between A and X' which is weakly- or non-bonding, and an unoccupied antibonding MO. However, neither of these approaches addresses the question as to how these interactions form, with the difficulty arising as, usually, the main group element $\mathrm{A}$ is electronrich, having one or more lone-pairs of electrons, as does the donor atom, $X^{\prime}$, so that a repulsive interaction might be anticipated. Theory has evolved to explain the specific nature of this interaction as being one formed between a region of positive electropositive potential located at the apex of a lone-pair of electrons of $X^{\prime}$ being donated to A, specifically to a partially occupied orbital of appropriate symmetry [21]. This electropositive region on the lone-pair is termed a $\sigma$-hole and the concept is related to the concepts/interactions responsible for the ubiquitous halogen bonding [16]. The electron deficiency of a given $\sigma$-hole will increase with increasing electronegativity of the substituents covalently bound to and with the size of the A atom, i.e. polarisability. With the foregoing in mind, the terminology for a secondary bond follows that of a hydrogen bond whereby A is the acceptor of a lone-pair of electrons from X'.

Such is the resurgence of interest in secondary bonding interactions, sparked largely by crystal engineering considerations, that specialised names have been coined for interactions involving the Group 15, 16 and 17 elements, namely tetrel [22], pnictogen [23] and chalcogen [24] bonding, respectively. In the following section, examples of tetrel, pnictogen and chalcogen bonding are presented and in Section 2.3, an overview of steric influences upon the formation of secondary bonding interactions is given.

\subsection{Examples of tetrel, pnictogen and chalcogen secondary bonding}

In this section, examples of tetrel, pnictogen and chalcogen bonding are presented. For the first-named, tetrel, bonding, the coordination geometry about the lead(II) atom in $\mathrm{Pb}(\mathrm{HL})(\mathrm{NCS})_{2}[25]$ is defined by $\mathrm{N}_{2} \mathrm{O}$ donors derived from the protonated (at the pyridyl- $\mathrm{N}$ 
atom) but, electrically neutral, tridentate Schiff base ligand as well as two negatively charged $\mathrm{N}$-bound thiocyanate anions. Having a rather large void in its coordination sphere, the lead centre is defined as being hemi-directional [26], a situation which allows for the close approach of two thiocyanate-S atoms at distances of 3.40 and $3.47 \AA$ in the crystal, i.e. well within the sum of the van der Waals radii of $3.82 \AA$ [27]. As illustrated in Fig. 1a, the consequence of these tetrel interactions is the formation of a supramolecular chain with a step topology. Computational chemistry was also employed to probe the tetrel bond energies [25]. The binding energy afforded by each $\mathrm{Pb}^{\cdots} \mathrm{S}$ interaction was estimated to be approximately 7 $\mathrm{kcal} / \mathrm{mol}$.

The example chosen to illustrate pnicotgen secondary bonding is drawn from xanthate, $-\mathrm{S}_{2} \mathrm{COR}$, chemistry [28a]. As shown in Fig. 1b, two molecules of $\mathrm{Sb}\left(\mathrm{S}_{2} \mathrm{COMe}\right)_{3}$ associate via two $\mathrm{Sb}^{\cdots \mathrm{S}}$ pnicotgen interactions to form a binuclear, zero-dimensional aggregate [28b]. Each individual molecule approximates mirror symmetry with one xanthate ligand lying on the putative plane with the others related across the plane. This leaves a large void allowing for the close approach of a centrosymmetric molecule and the formation of the central, rectangular $\left\{\mathrm{Sb}-\mathrm{S}^{\cdots}\right\}_{2}$ synthon. The curious feature of this structure is its variance with higher homologues, i.e. in the two polymorphic forms of the $\mathrm{R}=$ Et compound [28c, d], $\mathrm{R}=\mathrm{iPr}[28 \mathrm{e}]$, etc. [28d] which often either crystallise with the antimony(III) lying on a crystallographic 3fold axis or having approximate 3-fold symmetry [28d]. Clearly, the $\mathrm{Sb} \cdots \mathrm{S}$ pnicotgen interactions at play in $\mathrm{Sb}\left(\mathrm{S}_{2} \mathrm{COMe}\right)_{3}$ exert a significant influence upon the coordination geometry about the antimony(III) atom [29]. The question then arises: how does this structural diversity occur, a question partially addressed in Section 2.3. 


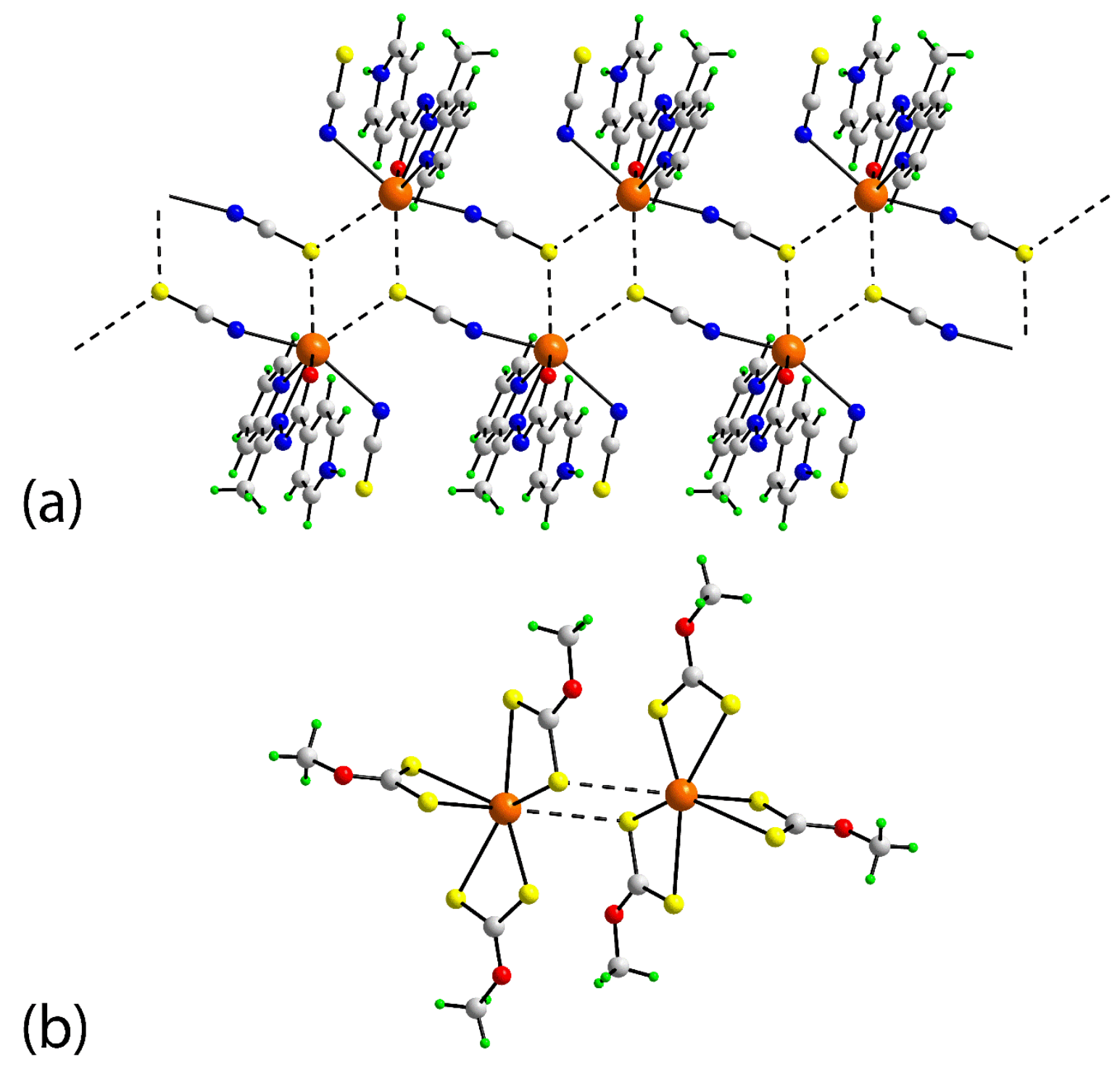

(c)

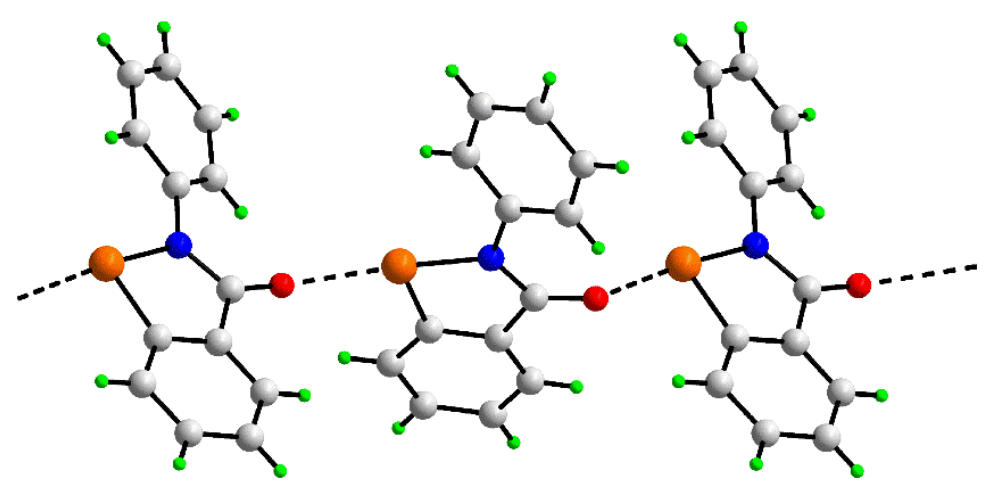

Figure 1. Supramolecular aggregation patterns in the crystal structures of (a) $\mathrm{Pb}(\mathrm{HL})(\mathrm{NCS})_{2}$ $\left(\mathrm{Pb} \cdots \mathrm{S}=3.40,3.47 \AA\right.$ 只 $[25],(\mathrm{b}) \mathrm{Sb}\left(\mathrm{S}_{2} \mathrm{COMe}\right)_{3}\left(\mathrm{Sb}^{\cdots} \mathrm{S}=3.52 \AA\right)$ [28b] and (c) Ebselen ${ }^{\circledR}\left(\mathrm{Se}^{\cdots} \mathrm{O}\right.$ $=3.52 \AA)[30 \mathrm{~d}]$, mediated by tetrel $\left(\mathrm{Pb}^{\cdots} \mathrm{N}\right)$, pnicogen $\left(\mathrm{Sb}^{\cdots} \mathrm{S}\right)$ and chalogen $(\mathrm{Se} \cdots \mathrm{N})$ secondary 
bonding, respectively. Colour code in this and subsequent figures: key metal centre, orange; sulphur, yellow; red, oxygen; nitrogen, blue; carbon, grey; hydrogen, bright-green.

The example used to highlight chalcogen secondary bonding has some biological

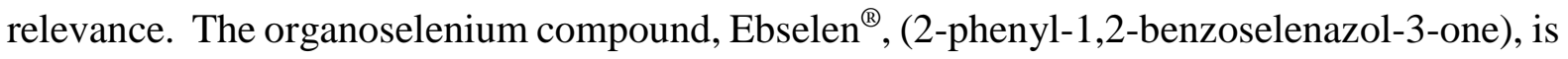
known as a synthetic glutathione peroxidase mimic being able to reduce hydrogen peroxide [30a] and is a key member of the emerging selenium pharmacopoeia [30b,c]. It was only very recently that the crystal structures of two polymorphs of Ebselen® were described, and each features $\mathrm{Se}^{\cdots} \mathrm{O}$ chalcogen secondary bonding [30d]. In the monoclinic form, twisted supramolecular chains are sustained by $\mathrm{Se}^{\cdots} \mathrm{O}$ interactions as shown in Fig. 1c; similar chains are found in the orthorhombic form but, with supporting $\mathrm{C}-\mathrm{H}^{\cdots} \mathrm{Se}$ contacts [30d]. The $\mathrm{Se} \mathrm{e}^{\cdots} \mathrm{O}$ separations of 2.52 and $2.53 \AA$ in the two forms, respectively, are reported to be tightest of their type and compare with the sum of the van der Waals radii of $3.41 \AA$ [27]. Computational chemistry was also used in the investigation and suggested the stabilisation energy afforded by the $\mathrm{Se}^{\cdots} \mathrm{O}$ interaction is $\sim 8 \mathrm{kcal} / \mathrm{mol}$ [30d]. The ability of selenium to engage in pnicotgen interactions is suggested to be crucial in the mechanism of action of Ebselen ${ }^{\circledR}$ and related species as for the former, the $\mathrm{Se}-\mathrm{N}$ bond needs to be cleaved as a prerequisite to its biological action [30a,d].

\subsection{Steric effects and secondary bonding}

Over the years a significant body of structural data has been accumulated with now well over 850,000 structures deposited in the CSD [19b]. This observation partly reflects the relative ease associated with routine structure determination employing crystallographic methods and also the wide availability of X-ray diffractometers in the chemical crystallography community and beyond. This has the consequence that many derivative structures, i.e. 
structures that only differ in a remote substituent, are now available for comparison. It is a long-held principle that careful analysis of closely related structures can reveal much about supramolecular association [31]. It is through systematic analyses of this wealth of structural data in the CSD, i.e. "data mining", that meaningful conclusions might be made concerning molecular packing and one such series of structures to be discussed are the binary mercury(II) dithiocarbamates, i.e. compounds of general formula $\mathrm{Hg}\left(\mathrm{S}_{2} \mathrm{CNRR}\right)_{2}$ for which there are currently 36 distinct examples available in the crystallographic literature [32a]; R, R' = alkyl, aryl. Early work on these and related classes of structures resulted in a proposal whereby steric effects associated with remote organic substituents, e.g. $\mathrm{R}$ and $\mathrm{R}^{\prime}$ in $\mathrm{Hg}\left(\mathrm{S}_{2} \mathrm{CNRR}\right)_{2}$, and in the case of organometallic compounds, the metal-bound $\mathrm{R}$ group, could be exploited to moderate the formation of secondary interactions [32b,c]. As an illustration of this principle, a summary of the available structural data for $\mathrm{Hg}\left(\mathrm{S}_{2} \mathrm{CNRR}\right)_{2}$ is given. In short, the concept states that owing to steric hindrance, large R/R' groups preclude the close approach of molecules with the result that secondary interactions, i.e. $\mathrm{Hg} \cdots \mathrm{S}$ for $\mathrm{Hg}\left(\mathrm{S}_{2} \mathrm{CNRR}\right)_{2}$, cannot form.

As illustrated in Fig. 2a, the structure of $\mathrm{Hg}\left(\mathrm{S}_{2} \mathrm{CNCy}_{2}\right)_{2}$ [33a], featuring bulky cyclohexyl substituents, is molecular with the mercury(II) centre within an $\mathrm{S}_{4}$ donor set that defines a distorted tetrahedral geometry. There is no evidence for intermolecular $\mathrm{Hg}^{\cdots} \mathrm{S}$ interactions in the molecular packing; there are three other structures in the $\operatorname{Hg}\left(\mathrm{S}_{2} \mathrm{CNRR}\right)_{2}$ series adopting this structural motif, all with bulky R/R' groups [31a]. When the bulk of the $\mathrm{R} / \mathrm{R}^{\prime}$ substituents decreases, as in $\mathrm{Hg}\left(\mathrm{S}_{2} \mathrm{CN}-\mathrm{iBu}_{2}\right)_{2}$ [33b], the tetrahedrally coordinated molecules align in the crystal structure to form very weak $\mathrm{Hg} \cdots \mathrm{S}$ interactions, significantly longer than the sum of the van der Waals radii, i.e. $3.35 \AA$ [27]. $\operatorname{In} \mathrm{Hg}\left(\mathrm{S}_{2} \mathrm{CN}-\mathrm{iBu}_{2}\right)_{2}$, the $\mathrm{Hg}{ }^{\cdots} \mathrm{S}$ separation between centrosymmetrically related molecules is $3.73 \AA$ [33b]. So a tendency to dimerise is evident but, the steric bulk of the iBu groups precludes the close approach of the molecules. Circumstances change with small R/R' substituents as now molecules form 
binuclear aggregates as illustrated in Fig. $2 \mathrm{c}$ for the archetypal compound, $\mathrm{Hg}\left(\mathrm{S}_{2} \mathrm{CNEt}\right)_{2}$ [33c,d], because two dithiocarbamate ligands are simultaneously chelating one mercury(II) atom while bridging the second, while the other two ligands remain in the chelating mode. About half of the $\mathrm{Hg}\left(\mathrm{S}_{2} \mathrm{CNRR}\right)_{2}$ structures adopt this motif in which the transannular $\mathrm{Hg}{ }^{\cdots} \mathrm{S}$ distance is normally longer than the bridging $\mathrm{Hg}-\mathrm{S}$ bond [32a].

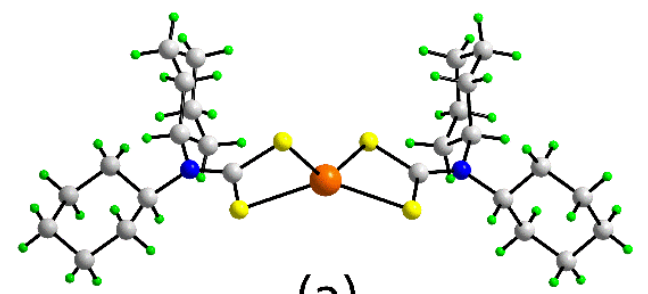

(a)
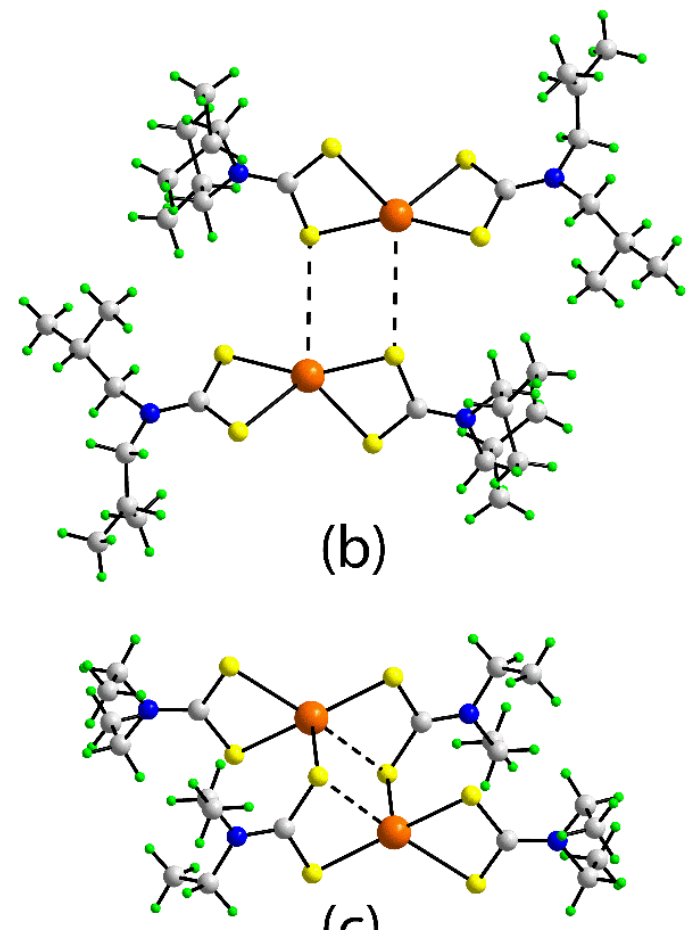

(c)

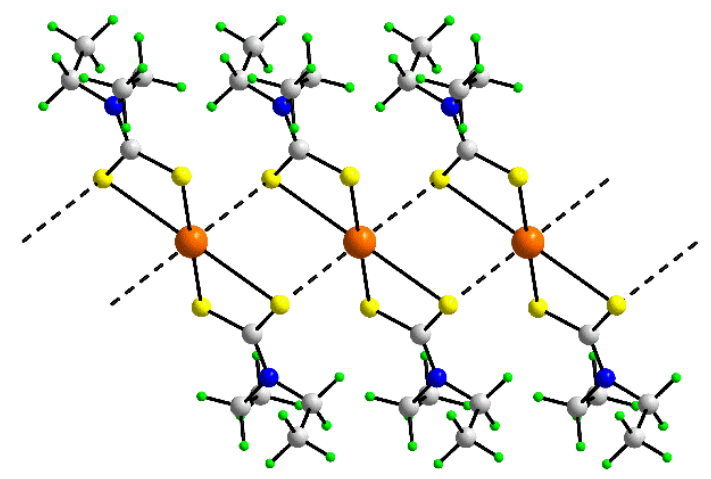

(d)

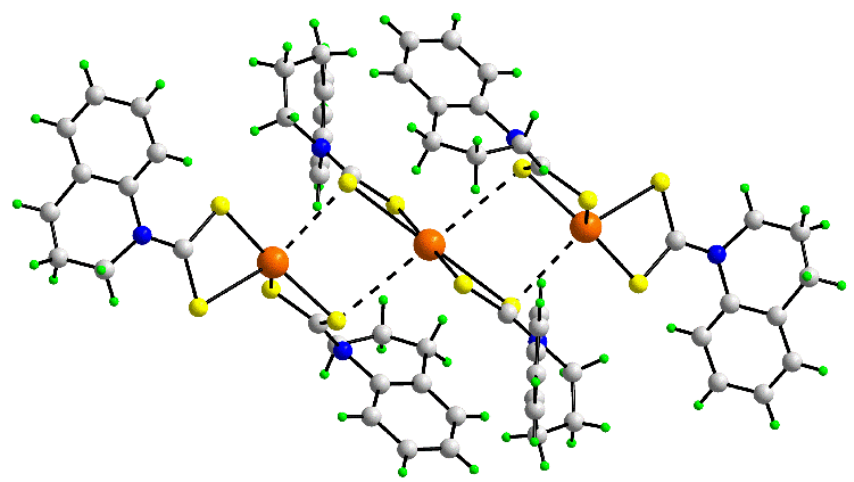

(e)

Figure 2. Supramolecular aggregation patterns in binary mercury(II) dithiocarbamates: (a) monomeric $\mathrm{Hg}\left(\mathrm{S}_{2} \mathrm{CNCy}_{2}\right)_{2}$ [33a], (b) pseudo binuclear $\left[\mathrm{Hg}\left(\mathrm{S}_{2} \mathrm{CN}-\mathrm{i}-\mathrm{Bu}\right)_{2}\right]_{2}(\mathrm{Hg} \cdots \mathrm{S}=3.73 \AA)$ [33b], (c) binuclear $\left[\mathrm{Hg}\left(\mathrm{S}_{2} \mathrm{CNEt}_{2}\right)_{2}\right]_{2}(\mathrm{Hg} \cdots \mathrm{S}=3.13 \AA) \quad[33 \mathrm{c}, \mathrm{d}]$, (d) one-dimensional $\left[\mathrm{Hg}\left(\mathrm{S}_{2} \mathrm{CNEt}_{2}\right)_{2}\right]_{\mathrm{n}} \quad\left(\mathrm{Hg} \cdots \mathrm{S}=3.31 \AA \AA \quad[33 \mathrm{c}]\right.$ and $\quad(\mathrm{e})$ trinuclear $\left\{\mathrm{Hg}\left[\mathrm{S}_{2} \mathrm{CN}(1,2,3,4-\right.\right.$ 
tetrahydroquinoline) $\left.]_{2}\right\}_{3}$ (central- $\mathrm{Hg} \cdots \mathrm{S}=3.37 \AA$ A outer- $\mathrm{Hg} \cdots \mathrm{S}=3.05 \AA$ ) [33e]. When present, $\mathrm{Hg} \cdots \mathrm{S}$ secondary bonding interactions are indicated by black dashed lines.

The above notwithstanding, there is clearly a fine balance between steric effects and supramolecular aggregation via $\mathrm{Hg}^{\cdots} \mathrm{S}$ secondary bonding interactions. This is nicely seen in the structure of a second polymorph of $\mathrm{Hg}\left(\mathrm{S}_{2} \mathrm{CNEt}_{2}\right)_{2}$ [33c], which unlike that illustrated in Fig. 2c, with on average one $\mathrm{Hg}^{\cdots} \mathrm{S}$ interaction per molecule, each is connected into a linear supramolecular chain with two $\mathrm{Hg}^{\cdots} \mathrm{S}$ interactions, on average, per square planar molecule leading to a 4+2 distorted octahedral geometry as shown in Fig. 2d. Finally, an intermediate structure is found for $\mathrm{Hg}(1,2,3,4 \text {-tetrahydroquinolinedithiocarbamate })_{2}$ which is trinuclear [33e], Fig 2e. The centrosymmetric aggregate features a central mercury(II) atom within 4+2 distorted octahedral geometry, as seen for the polymeric polymorph of $\mathrm{Hg}\left(\mathrm{S}_{2} \mathrm{CNEt}_{2}\right)_{2}$ [33c], Fig. 2d, with the links between this and the outer residues being two distinct $\mathrm{Hg} \cdots \mathrm{S}$ secondary bonding interactions. Clearly, other factors such as global crystal packing effects exert a significant influence in determining the ultimate structural motif in these and related compounds and it remains an enormous challenge to rationalise all structural motifs, let alone control their formation. In summary, as a first principle, steric factors account for an overwhelming majority of the structures adopted by this type of compound, and can influence the adoption of other supramolecular motifs discussed later.

\section{$3 \quad$ Metal $\cdots$ metal interactions in supramolecular chemistry}

\subsection{Overview}

Interactions between metal centres is the other area in supramolecular chemistry of metal-based compounds that has long attracted the interest of coordination chemists [34]. Such interactions arise owing to relativistic effects which exert their maximum influence for the heavier elements [35]. In short, relativistic effects result in electrons in $s$ orbitals being more 
tightly held to the nucleus with concomitant reduction in the strength of binding of electrons residing in the $d$ and $f$ orbitals, as applicable. This effect is at a maximum for gold which explains the "inertness" of this element and its tendency to form $\mathrm{Au}$ “Au interactions. Indeed, the study of $\mathrm{Au}{ }^{\cdots} \mathrm{Au}$ interactions is a mature discipline and some highlights are included in Section 3.2. Following this is an overview of other $\mathrm{M} \cdots \mathrm{M}$ interactions and then, in Section 3.4, some examples of interactions occurring between different metal centres, i.e. $\mathbf{M}^{\cdots \cdots} \mathbf{M}^{\prime}$, are given.

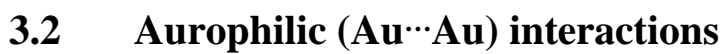

Contacts between closed-shell $\left(5 d^{10}\right)$ gold(I) centres which can occur intra-, inter- or both intra- and inter-molecularly highlight the aurophilicity of gold [36] and are usually termed aurophilic bonding/interactions. An example of a structure featuring intra- and inter-molecular aurophilic interactions is shown in Fig. 3a, i.e. a twisted, supramolecular chain comprising $\left.\left\{\left[\mathrm{Au}_{2}\left(\mathrm{~S}_{2} \mathrm{CNEt}\right)_{2}\right)\right]_{2}\right\}_{\mathrm{n}}$, a molecule still attracting considerable interest in terms of solvent- and pressure-dependent polymorphism [37]. In keeping with the comments on steric hindrance as a crucial factor in supramolecular assembly in Section 2.3, gold(I) compounds are often linear allowing the close approach of proximate molecules to enable the formation of $\mathrm{Au}{ }^{\cdots} \mathrm{Au}$ contacts. Conversely, when large substituents are present, such as $\mathrm{Cy}_{3} \mathrm{P}, \mathrm{Au} \cdots \mathrm{Au}$ contacts do not form [38] owing to the obvious steric crowding that would ensue. The length of an $\mathrm{Au}{ }^{\cdots} \mathrm{Au}$ contact can span a relatively large range of 2.7 to $3.5 \AA$. In this context, very recently the pressure-dependence of an intermolecular $\mathrm{Au} \cdots \mathrm{Au}$ interaction was evaluated where it was found that the magnitude of $\mathrm{Au}{ }^{*} \mathrm{Au}$ contact in the crystal structure of $[1,4-$ $\left.\mathrm{C}_{6} \mathrm{H}_{4}\left\{\mathrm{PPh}_{2}(\mathrm{AuCl})\right\}_{2}\right]$ contracted from $3.67 \AA$, under conditions of ambient pressure, to $3.06 \AA$ at 106.2 kbar [39]. Recent authoritative reviews on aurophilic interactions are available that highlight the fascinating diversity of supramolecular architectures they sustain [40]. What 
follows are examples of supramolecular structures featuring aurophilic interactions chosen to highlight the interesting structural chemistry for these compounds.

The energy associated with an aurophilic interaction spans the range of $6-12 \mathrm{kcal} / \mathrm{mol}$ [41], an observation crucial to the crystal engineer as this energy of stabilisation is comparable to that afforded by conventional hydrogen bonding. This gives rise to the possibility of seeing aurophilic and hydrogen bonding interactions acting in concert or indeed, in competition [42ac]. A recent survey of gold compounds containing amide or carboxylic acid functionality indicated, not surprisingly, that hydrogen bonding predominates but both modes of supramolecular association can co-exist [42d]. Two illustrative examples are shown in Fig. 3. In the first, centrosymmetrically related molecules of $\mathrm{tBuN} \equiv \mathrm{CAu}\left(\mathrm{SC}_{6} \mathrm{H}_{4} \mathrm{CO}_{2} \mathrm{H}-4\right)$ assemble via the eight-membered, carboxylic acid synthon, $\{\cdots \mathrm{HOCO}\}_{2}$, to which are associated, via $\mathrm{Au}{ }^{\cdots} \mathrm{Au}$ interactions, two further molecules, each with an intramolecular hydroxyl-O-H${ }^{\cdots} \mathrm{S}$ (thiolate) hydrogen bond that closes a six-membered loop [43], Fig. 3b. The second example is a phosphane analogue of that just described, i.e. $\mathrm{Me}_{2}(\mathrm{Ph}) \mathrm{PAu}\left(\mathrm{SC}_{6} \mathrm{H}_{4} \mathrm{CO}_{2} \mathrm{H}-4\right)$ [44]. Similar hydrogen binding is found but now the $\mathrm{Au}^{\cdots} \mathrm{Au}$ interactions connect molecules into a chain leading to a supramolecular ladder, Fig. 3c. 


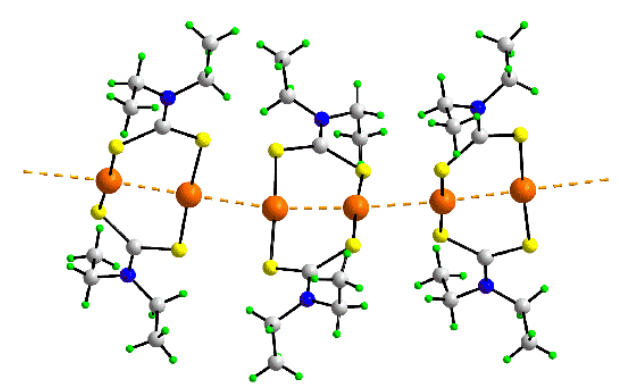

(a)

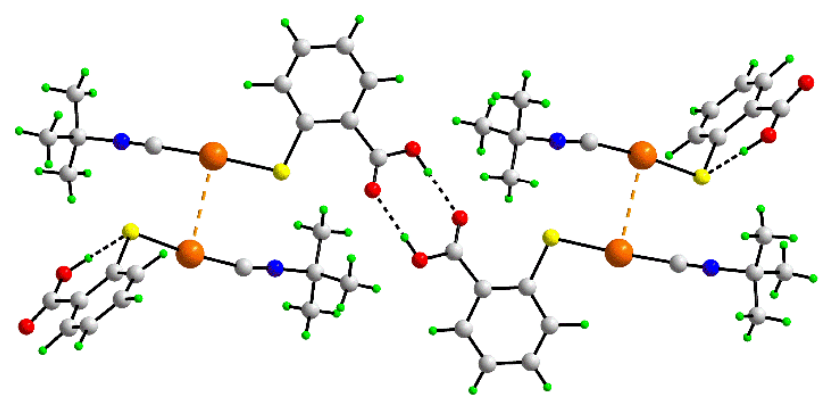

(b)

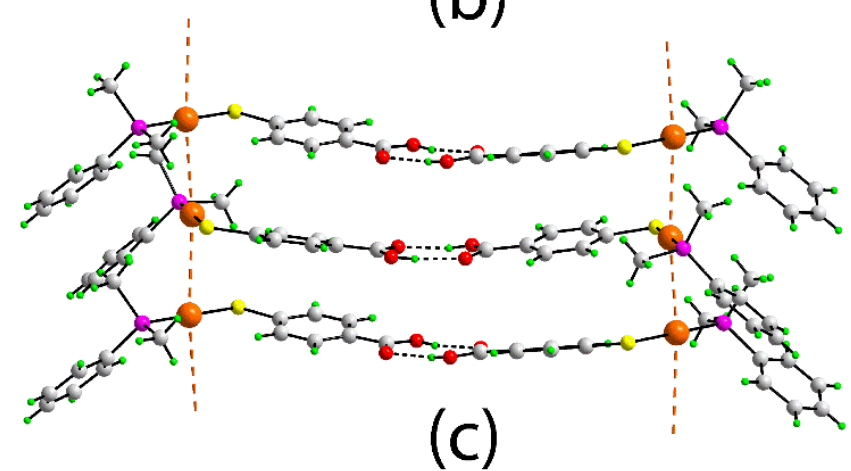

Figure 3. Supramolecular aggregation patterns sustained by $\mathrm{Au}^{\cdots} \mathrm{Au}$ interactions (gold dashed lines): (a) twisted, supramolecular chain in $\left\{\left[\mathrm{Au}\left(\mathrm{S}_{2} \mathrm{CNEt}_{2}\right)\right]_{2}\right\}_{\mathrm{n}}[37]$, (b) tetranuclear aggregate in $\mathrm{tBuN} \equiv \mathrm{CAu}\left(\mathrm{SC}_{6} \mathrm{H}_{4} \mathrm{CO}_{2} \mathrm{H}-4\right)$ [43] with carboxylate-O- $-\mathrm{H}^{\cdots} \mathrm{O}$ (carboxylate) and hydroxyl-O$\mathrm{H}^{\cdots} \mathrm{S}$ (thiolate) hydrogen bonding shown as black dashed lines and (c) supramolecular ladder in $\mathrm{Me}_{2}(\mathrm{Ph}) \mathrm{PAu}\left(\mathrm{SC}_{6} \mathrm{H}_{4} \mathrm{CO}_{2} \mathrm{H}-4\right)$ [44]. Additional colour code: phosphorus, pink.

A practical consequence of forming aurophilic interactions is the impact on luminescence [45], as the formation of an aurophilic interaction reduces the gap between the energy levels of the transition states and may increase the transition probability. As such, 
aurophilic interactions often exert a significant influence upon both gold-centred transitions as well as ligand-to-gold charge transfer transitions [45]. Luminescence events can also be a signal for other processes occurring in crystals. Thus, when subjected to external influences including light, thermal, mechanical and chemical, rearrangements in the crystal can occur giving rise to, often, drastic differences in solid-state luminescence responses [46a]. Drawing upon an example with crystal structures available for both before and after stimulus, the polymorph structures of $[\mathrm{PhAuC} \equiv \mathrm{NPh}][46 \mathrm{~b}]$ are described. Rapid recrystallisation of $[\mathrm{PhAuC} \equiv \mathrm{NPh}]$ gave a triclinic structure whereby there were no $\mathrm{Au} \cdots \mathrm{Au}$ interactions between molecules with the shortest separation being $4.73 \AA$ A, Fig. 4a. Slow evaporation from the same solvent system gave a tetragonal polymorph featuring $\mathrm{Au}^{\cdots}{ }^{\cdots} \mathrm{Au}$ interactions of $3.18 \AA$, Fig. 4b, as a result of significant reorganisation of the molecules, e.g. co-planar to a partially crossed arrangement when viewed down the respective $\mathrm{Au}$ “'Au vectors, Fig. 4. Mechanical stimulus in the form of a simple touch by a needle, let alone mechanical grinding, resulted in a singlecrystal-single-crystal phase transformation with dramatic changes in the photoluminescence, i.e. blue to yellow-green [46b]. 

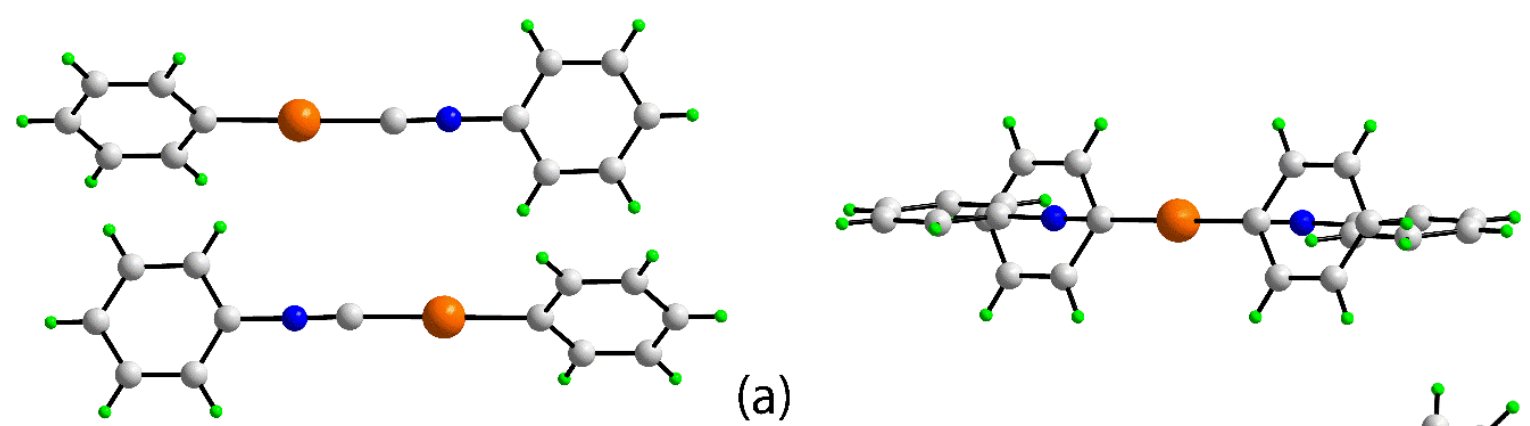

(a)
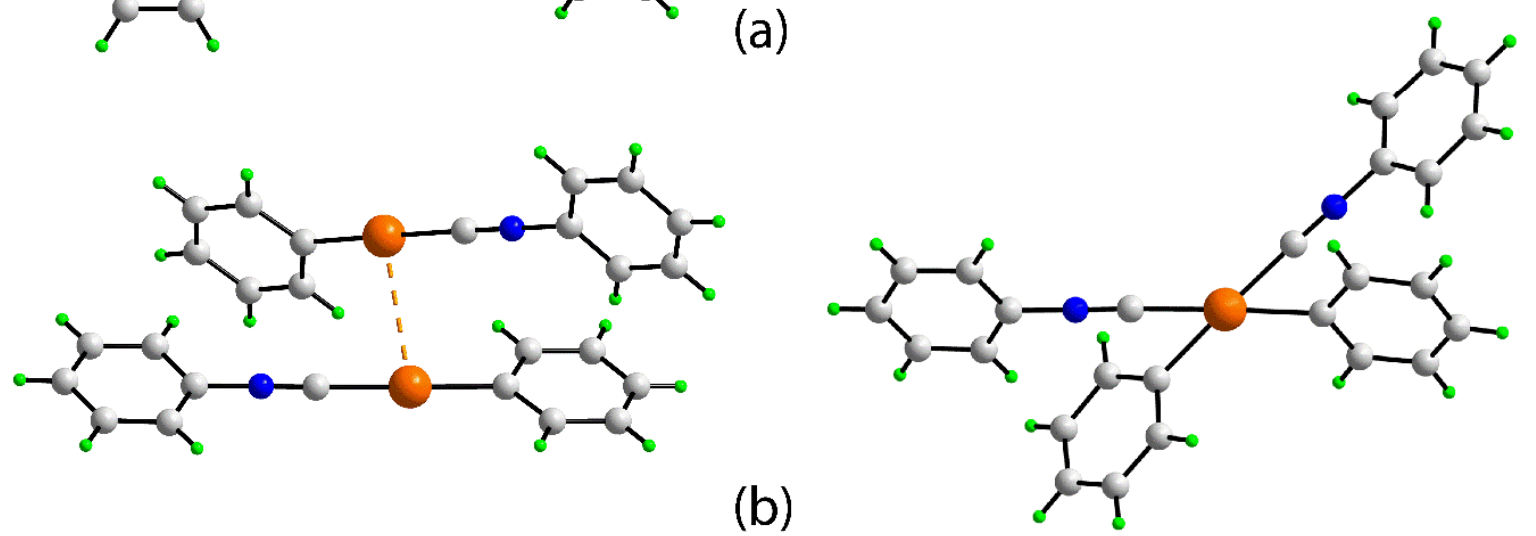

(b)

Figure 4. Molecular structures of $[\mathrm{PhAuC} \equiv \mathrm{NPh}][46 \mathrm{~b}]$ found in the (a) triclinic and (b) tetragonal polymorphs, highlighting the significant reorganisation in the molecular packing owing to a mechanical trigger. The $\mathrm{Au}{ }^{*} \cdot \mathrm{Au}$ separations in the two views are 5.73 and $3.18 \AA$, respectively.

Exploiting gold's ability to form aurophilic interactions and consequent influence on electronic states has led to the use of luminescence properties of gold compounds as chemosensors [47a]. An example of this concept for which a crystal structure determination is available to complement the solution studies is found in $\left[\mathrm{Au}_{2}\left(\mu-\mathrm{S}_{2} \mathrm{CNEt}_{2}\right)\left(\mathrm{Ph}_{2} \mathrm{~PB} 15 \mathrm{C} 5\right)_{2}\right]^{+}$ where B15C5 is benzo-15-crown-5 [47b]. Based on related systems and spectroscopy, the cation is supposed to have an open conformation with no evidence for $\mathrm{Au}^{\cdots}{ }^{\cdots} \mathrm{Au}$ interactions. However, when presented with alkali metal ions, e.g. $\mathrm{Na}^{+}$, complexation occurs to bring the two macrocycles in close proximity leading to the formation of an intramolecular $\mathrm{Au} \cdots \mathrm{Au}$ interactions, Fig. 5, and a concomitant luminescence response; fine tuning of the macrocycles can lead to speciation. 


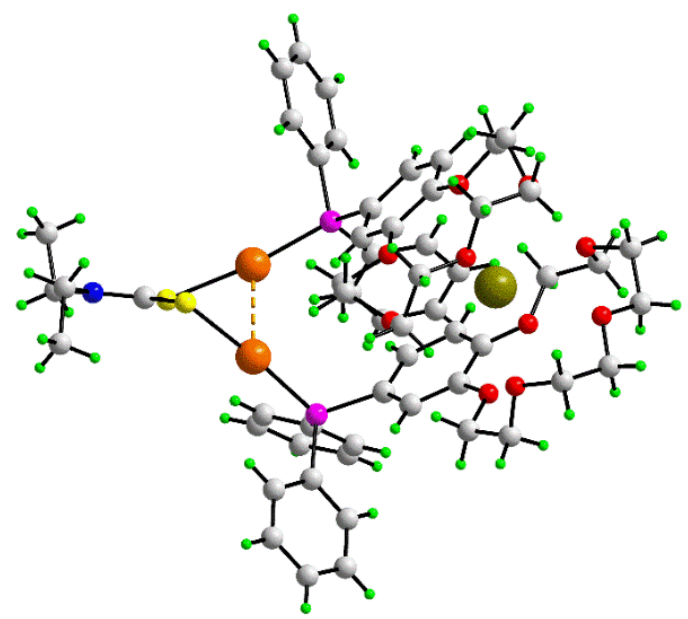

Figure 5. Molecular structure of the $\left[\mathrm{Au}_{2}\left(\mu-\mathrm{S}_{2} \mathrm{CNEt}_{2}\right)\left(\mathrm{Ph}_{2} \mathrm{~PB} 15 \mathrm{C} 5\right)_{2}\right]^{+}$cation $[47 \mathrm{~b}]$ showing a $\mathrm{Au}^{\cdots}{ }^{\cdots} \mathrm{Au}$ interaction $(3.08 \AA$ ) formed as a result of complexation of the macrocyclic residues to $\mathrm{Na}^{+}$cations. Anions and solvent are omitted. Additional colour code: sodium, olive-green.

The foregoing has focussed exclusively upon $\mathrm{Au}^{\cdots} \mathrm{Au}$ interactions involving gold(I) species. However, such interactions involving gold(III), being isoelectronic with platinum(II) (see below), are starting to emerge in the literature. Thus, gold(III) centres can associate via $\mathrm{Au}^{\cdots} \mathrm{Au}$ interactions as illustrated by the structure of $\left\{\left[2-\left(2,2^{\prime}-\right.\right.\right.$ bipyridin-6-yl $)$ phenyl][(4(dimethylamino)phenyl)ethynyl]gold(III) $\}^{+}$where the $\mathrm{Au}^{\cdots} \mathrm{Au}$ separation between centrosymmetrically related molecules is $3.50 \AA$ [48], Fig. 6.

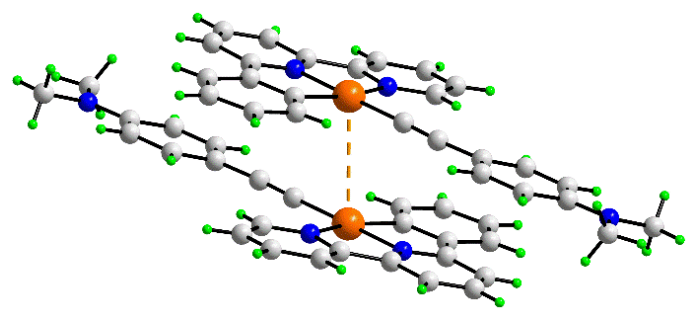

Figure 6. Illustration of a $\mathrm{Au} \cdots \mathrm{Au}$ interactions involving gold(III) centres in the centrosymmetric aggregate formed by two \{[2-(2,2'-bipyridin-6-yl)phenyl]-[(4- 
(dimethylamino)phenyl)ethynyl]gold(III) $\}^{+}$cations [48]; anion and solvent molecules are omitted.

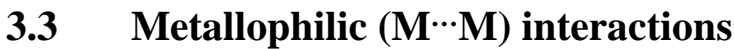

Other metal centres in complexes with low coordination numbers, i.e. accessible to the close approach of other molecules, can exhibit metallophilic, $\mathbf{M} \cdots \mathbf{M}$, interactions which again arise from relativistic effects. With the foregoing influence of relativistic effects in mind, it is not surprising that the elements on either side of gold in the Periodic Table, i.e. platinum and mercury have attracted significant attention in terms of platinophilic [49] and mercurophilic [50] interactions, respectively, in their crystal structures. The formation of molecular wires sustained by $\mathrm{Pt} \cdots \mathrm{Pt}$ interactions, as in the crystal structure of (2-(1-hexyl-1H-1,2,3-triazol-4yl)pyridine)-(2-(pyridin-2-yl)phenyl)-platinum tetrafluoridoborate [51], illustrated in Fig. 7a

with $\mathrm{Pt}^{\cdots}$ Pt separations of $3.65 \AA$, motivates much of the work in platinum chemistry. On the other hand, the dimeric aggregate in the molecular packing of methylmercury(2-mercapto-4methylpyrimidinate) was reported as an early example highlighting unusual mercurophilic interactions of $3.10 \AA$ A between molecules related by 2-fold symmetry [52], Fig. 7b.

\section{(a)}

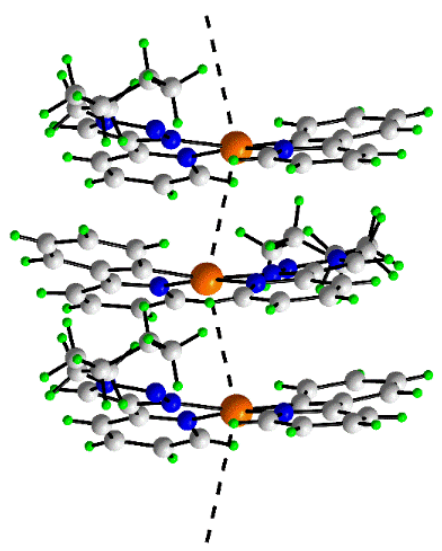

(b)

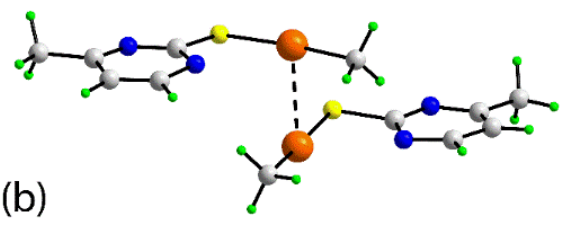


Figure 7. (a) Platinophilic $(\mathrm{Pt} \cdots \mathrm{Pt}=3.65 \AA)$ interactions lead to a zig-zag $\{\cdots \mathrm{Pt}\}_{\mathrm{n}}$ supramolecular chain of cations in the structure of (2-(1-hexyl-1H-1,2,3-triazol-4-yl)pyridine)(2-(pyridin-2-yl)phenyl)platinum(II) tetrafluoridoborate [51] (anions omitted) and (b) a mercurophilic $(\mathrm{Hg} \cdots \mathrm{Hg}=3.10 \AA)$ interaction sustains a dimeric aggregate in the structure of methylmercury(2-mercapto-4-methylpyrimidinate) [52].

While other elements feature metallophilic interactions in their crystal structures, the one element that has garnered most attention in this regard is silver for which a recent comprehensive review is available [53]. Argentophilic interactions can play a role in photochemically-promoted [2+2] cycloaddition reactions in the solid-state, an area of considerable contemporary interest in both coordination and organic chemistry [54]. As shown in Fig. 8, two molecules of bis[trans-1-(4-pyridyl)-2-phenylethylene]-(trifluoroacetato)silver(I) are linked via an argentophilic interaction amounting to $3.44 \AA$ to form a dimeric aggregate. Crucially for solid-state [2+2] cycloaddition reactions, the double bonds of the trans-1-(4-pyridyl)-2-phenylethylene ligands are aligned so that when subjected to UV-light, a single crystal to single crystal (SCSC) reaction occurs to yield binuclear bis $\left[\mu_{2}-3,4-\right.$ diphenylcyclobutane-1,2-bis(4-pyridyl)]-bis(trifluoroacetato)-di-silver(I), containing two cyclobutane groups [55]. 


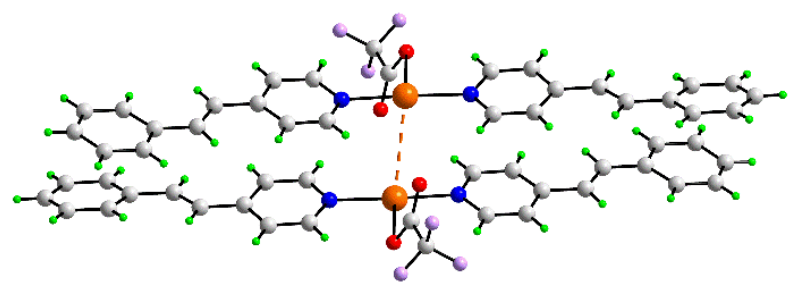

(a)

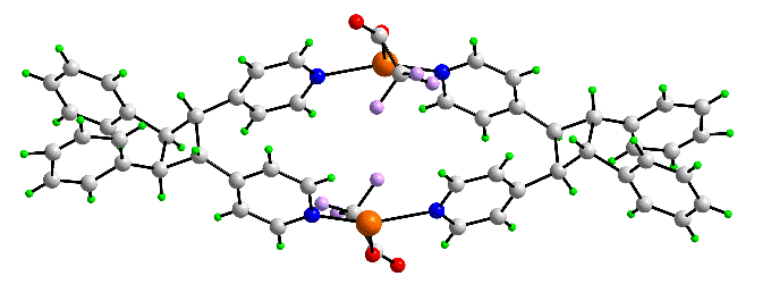

(b)

Figure $8 . \quad$ (a) Dimeric aggregate in tetrakis[trans-1-(4-pyridyl)-2-phenylethylene]bis(trifluoroacetato)-di-silver(I) sustained by an argentophilic ( $\mathrm{Ag} \cdots \mathrm{Ag}=3.44 \AA$ ) interaction, which upon irradiation with UV light undergoes a SCSC transformation via a $[2+2]$ cycloaddition reaction to yield (b) bis[ $\mu_{2}-3,4-$ diphenylcyclobutane-1,2-bis(4-pyridyl)]bis(trifluoroacetato)-di-silver(I) [55]. Disorder components of both molecules are omitted. Additional colour code: fluoride, lavender.

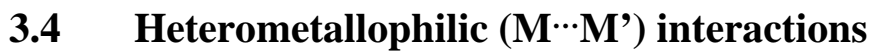

As indicated in Section 3.3, the key elements likely to form metallophilic interactions are those where relativistic effects are greatest [35]. Again, motivated largely by the desire to control luminescence events, increasing efforts have been devoted to form metallophilic interactions between different metal centres, e.g. $\mathrm{Au}{ }^{\cdots} \mathrm{Ag}$ [56a] and $\mathrm{Au}{ }^{\cdots} \mathrm{Hg}$ [56b]. Other heavy elements are also capable of forming metallophilic interactions, such as those with $5 \mathrm{~d}^{10} 6 \mathrm{~s}^{2}$ electronic configurations, namely thallium(I), lead(II) and bismuth(III). Owing to their weaker nature, their reports remain relatively sparse in the literature. However, if any of these elements is combined with metals with a greater propensity to form metallophilic interactions, stable aggregates may be formed. A case in point is the $\mathrm{Au} \cdots \mathrm{Pb}$ interaction found in the structure of 
$\left(\mathrm{C}_{6} \mathrm{Cl}_{5}\right)_{2} \mathrm{Au} \cdots \mathrm{Pb}\left[\mathrm{HB}(\mathrm{pz})_{3}\right]$ [57a], shown in Fig. $9 ; \mathrm{HB}(\mathrm{pz})_{3}$ is the hydrogen tris(pyrazolyl)borate anion. In this structure, the $\mathrm{Au}{ }^{\cdots} \mathrm{Pb}$ separation is $3.05 \AA$ and emission wavelength is $480 \mathrm{~nm}$ [57a]. The energy of association between the gold and lead atoms, having ionic and dispersive character strengthened by relativistic effects, was calculated to be ca $98 \mathrm{kcal} / \mathrm{mol}$. Substituting fluoride into the gold-bound aryl rings of $\left(\mathrm{C}_{6} \mathrm{Cl}_{5}\right)_{2} \mathrm{Au} \mathrm{Pb}\left[\mathrm{HB}(\mathrm{pz})_{3}\right]$, i.e. leading to $\left(\mathrm{C}_{6} \mathrm{Cl}_{2} \mathrm{~F}_{3}\right)_{2} \mathrm{Au}$ and $\left(\mathrm{C}_{6} \mathrm{Cl}_{5}\right)_{2} \mathrm{Au}$ anions, successively diminishes the strength of the $\mathrm{Au} \cdots \mathrm{Pb}$ interactions, i.e. to 3.10 and $3.28 \AA$, respectively [57b]. The consequence in terms of luminescence is that the emissions are shifted to higher energy, i.e. 468 and $396 \mathrm{~nm}$, respectively [57b]. Normally, attempts at rationalising small differences in the distances characterising weak interactions is often not possible/recommended [58] but, in this instance, systematic changes in chemistry result in systematic differences in the $\mathrm{Au} \cdots \mathrm{Pb}$ distances and correlated spectroscopic responses [57]. Such control over solid-state luminescence, i.e. by changing the metal centres participating in these interactions, the electronic structures of the ligands bound to the metals as well moderating the coordination geometries, ensures this field will attract increasing attention.

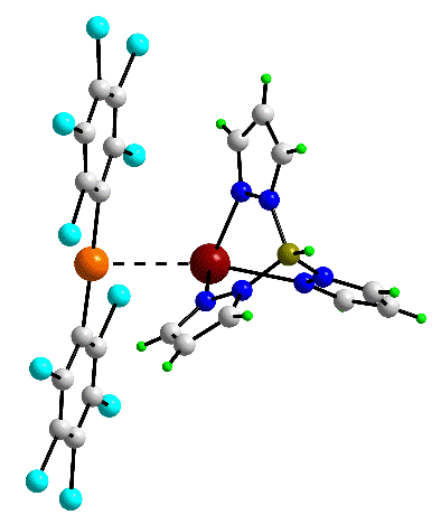

Figure 9. An illustrative example of a $\mathrm{Au} \cdots \mathrm{Pb}(=3.05 \AA)$ interaction found in the structure of $\left(\mathrm{C}_{6} \mathrm{Cl}_{5}\right)_{2} \mathrm{Au} \cdots \mathrm{Pb}\left[\mathrm{HB}(\mathrm{pz})_{3}\right]$ [57a]. Additional colour codes: chloride, cyan; boron, dark-yellow. 


\section{$4 \quad$ Metal $\cdots$ hydrogen interactions as supramolecular synthons}

Interactions between metals and hydrogen have been recognised for well over 40 years and may be classified in terms of agostic, anagostic and weak hydrogen bonds [59]. An agostic interaction is a three centre, two electron bond where the metal centre is electron-deficient, i.e. involves donation of electron density from a filled $\sigma_{\mathrm{C}-\mathrm{H}}$ orbital to the metal acting as a Lewis acid. By contrast, anagostic interactions are three centre, four electron interactions involving electron-rich metal centres which might be repulsive or attractive, and if attractive can be considered as a hydrogen bond with the metal centre functioning as the hydrogen bond acceptor [59]. Agostic interactions are generally characterised by $\mathrm{M} \cdots \mathrm{H}-\mathrm{C}$ distances of approximately 1.8 to $2.3 \AA$ and angles at $\mathrm{H}$ in the range ca 90 to $140^{\circ}$. On the other hand, anagostic interactions generally have longer $\mathrm{M} \cdots \mathrm{H}-\mathrm{C}$ distances, 2.3 to $2.9 \AA$, and wider angles, 110 to $170^{\circ}$. Metal $\cdots$ hydrogen bonding studies have focussed largely upon the metals platinum(II) [59, 60a], exploiting the NMR-active ${ }^{195} \mathrm{Pt}$ isotope, and gold, for which a comprehensive review has been published recently [60b].

Unambiguous crystallographic evidence, i.e. based on neutron diffraction data, for water- $\mathrm{O}-\mathrm{H} \cdots \mathrm{Pt}$ and ammine- $\mathrm{N}-\mathrm{H}^{\cdots} \mathrm{Pt}$ (non-conventional) hydrogen bonding was reported in the structure of trans-[ $\mathrm{PtCl}_{2}\left(\mathrm{NH}_{3}\right)(\mathrm{N}$-glycine)] [61]. As shown in Fig. 10, centrosymmetrically related molecules are connected via ammine- $\mathrm{N}-\mathrm{H} \cdots \mathrm{Pt}$ hydrogen bonds arranged in slightly buckled six-membered $\{\cdots \mathrm{HNPt}\}_{2}$ synthon. The water molecule, as an example of inverse coordination, associates with each platinum centre via a water- $\mathrm{O}-\mathrm{H}^{\cdots} \mathrm{Pt}$ hydrogen bond. The water molecule simultaneously forms donor and acceptor hydrogen bonds to the carbonyl and hydroxyl groups of the carboxylic acid residue. The hydrogen atoms occupy approximately trans positions about the square planar platinum(II) centre with the $\mathrm{H}^{\cdots} \mathrm{Pt} \cdots \mathrm{H}$ angle being $167^{\circ}$, giving rise to a pseudo [4+2] coordination geometry. Computational chemistry indicates the 
nature of the water-O-H...Pt hydrogen bond is neither electrostatic nor covalent but, rather driven by dispersion [61].

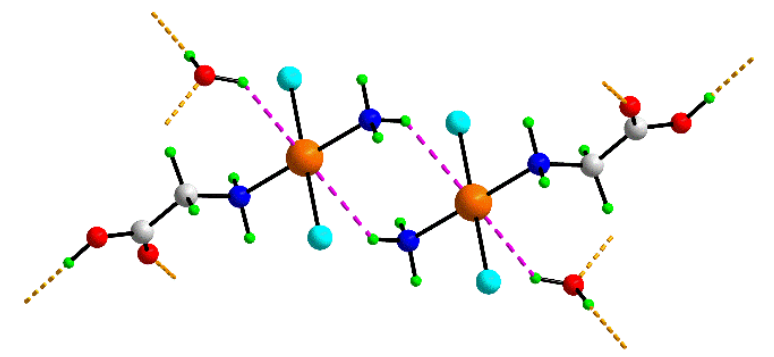

Figure 10. Crystallographic evidence for water-O-H ${ }^{\cdots} \mathrm{Pt}\left(\mathrm{H}^{\cdots} \mathrm{Pt}=2.89 \AA\right.$, angle at $\left.\mathrm{H}=137^{\circ}\right)$ and ammine- $\mathrm{N}-\mathrm{H}^{\cdots} \mathrm{Pt}\left(\mathrm{H}^{\cdots} \mathrm{Pt}=2.75 \AA\right.$, angle at $\left.\mathrm{H}=137^{\circ}\right)$ hydrogen bonding, shown as pink dashed lines, reported in the structure of trans-[ $\mathrm{PtCl}_{2}\left(\mathrm{NH}_{3}\right)(\mathrm{N}$-glycine)] [60]. Non-specified hydrogen bonds are shown as orange dashed lines.

Considerable effort in deciphering the nature of $\mathrm{C}-\mathrm{H}^{\cdots} \mathrm{M}$ interactions in nickel(II) and palladium(II) dithiocarbamate complexes has taken place in recent years [62]. Dithiocarbamate ligands are well-known for their propensity to form tight, four-membered chelate rings enabling significant delocalisation of $\pi$-electron density over the ring and in square-planar complexes, significant conjugation can be anticipated over the $\mathrm{M}\left(\mathrm{S}_{2} \mathrm{CN}\right)_{2}$ framework along with activation of the metal centre. An example of $\mathrm{C}-\mathrm{H} \cdots \mathrm{Ni}$ interactions leading to a supramolecular chain is found in the structure of bis[benzyl(3methoxybenzyl)carbamodithioato]nickel(II) [62c], shown in Fig. 11. Computational chemistry conducted on model compounds indicates the energy of stabilisation afforded by each $\mathrm{C}-\mathrm{H} \cdots \mathrm{Ni}$ interaction in this structure is $3.9 \mathrm{kcal} / \mathrm{mol}$ [62c]. 


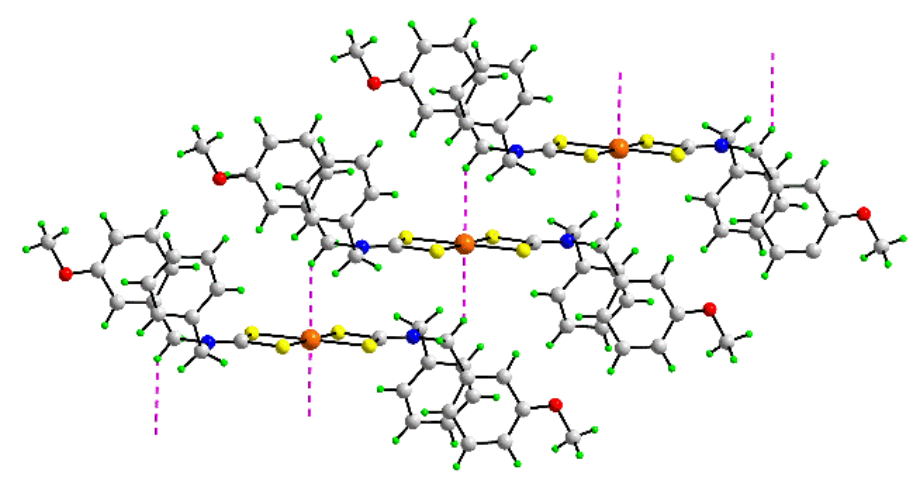

Figure 11. Supramolecular chain sustained by $\mathrm{C}-\mathrm{H}^{\cdots} \mathrm{Ni}$ interactions in the molecular packing of centrosymmetric bis[benzyl(3-methoxybenzyl)carbamodithioato]nickel(II) [62c]. The $\mathrm{H}^{\cdots} \mathrm{Ni}$ distance is $2.78 \AA$ and the angle at $\mathrm{H}$ is $137^{\circ}$.

In a recent but, rare systematic evaluation of the crystallographic literature for anagostic $\mathrm{C}-\mathrm{H} \cdots \mathrm{Ni} / \mathrm{Cu}$ interactions cum hydrogen bonding leading to eight-membered $\{\cdots \mathrm{HCNM}\}_{2}$ synthon, cf. the carboxylic acid dimer synthon $\left\{\cdots \mathrm{HOCO}_{2}\right.$, revealed the formation of zeroand one-dimensional aggregation patterns [63a]. Selected examples are shown in Fig. 12. The zero-dimensional aggregate formed by two centrosymmetrically related [ethylenebis(salicylideneiminato)]nickel(II) molecules sees methylene-H atoms interacting with symmetry related nickel(II) centres [63b]. A supramolecular chain mediated by $\{\cdots \mathrm{HCNNi}\}_{2}$ synthons, again involving methylene-H atoms, is formed in the structure of (6,14-diacetyl7,13-dimethyl-1,4,8,12-tetra-azacyclopentadeca-4,6,12,14-tetraenato)nickel(II) [63c], Fig. 12b. Finally, an unusual example of a two-dimensional architecture sustained by $\{\cdots \mathrm{HCNCu}\}_{2}$ synthons, involving methyl-H atoms, is observed in the molecular packing of cyclotetrakis[( $\mu_{2}$-dimethylamino)copper(I)] [63d], Fig. 12c. 


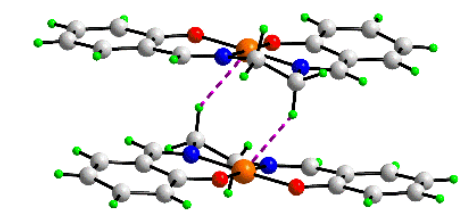

(a)

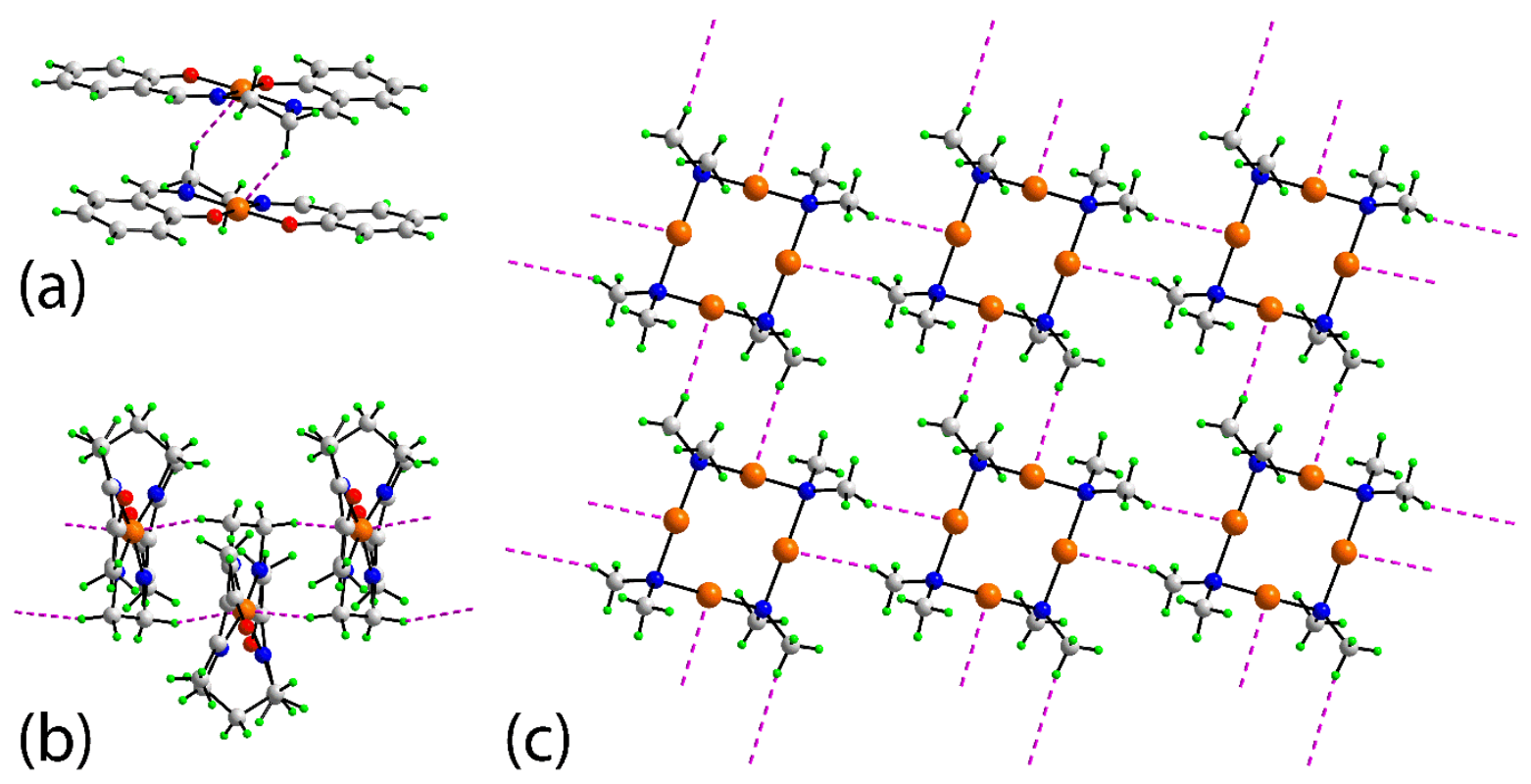

Figure 12. Supramolecular association sustained by $\mathrm{C}-\mathrm{H}^{\cdots} \mathrm{M}$ interactions in the molecular packings of (a) [ethylene-bis(salicylideneiminato)]nickel(II) with $\mathrm{H}^{\cdots} \mathrm{M}=2.95 \AA$ and angle at $\mathrm{H}=127^{\circ}$ [63b], (b) (6,14-diacetyl-7,13-dimethyl-1,4,8,12-tetra-azacyclopentadeca-4,6,12,14tetraenato)nickel(II) with $\mathrm{H}^{\cdots} \mathrm{M}=2.84 \AA$ and angle at $\mathrm{H}=154^{\circ}[63 \mathrm{c}]$ and (c) cyclo-tetrakis[( $\mu_{2-}$ dimethylamino)copper(I)] with $\mathrm{H}^{\cdots} \mathrm{M}=2.85 \AA$ and angle at $\mathrm{H}=155^{\circ}$ and $2.92 \AA$ and $160^{\circ}$ [63d]. Solvent molecules in (a) and (b) have been omitted.

With relevance to several key chemical process, e.g. catalytic transfer of hydrogen, it is likely the evaluation of metal $\cdots$ hydrogen interactions, including those relevant to supramolecular chemistry, will be an area that will continue to garner attention.

\section{$5 \quad$ Metal $\cdots \pi($ arene $)$ interactions}

\subsection{Preamble}

The participation of arene and other aromatic rings in supramolecular recognition is well known in the organic solid-state and in biological systems. The importance of face-toface ( $\pi-\pi$ stacking), off-set (slipped or parallel displaced) face-to-face and edge-to-face, i.e. 
$\mathrm{C}-\mathrm{H}^{\cdots} \pi$, interactions for the stabilisation of both crystal structures and molecular conformations is well established [64]. It is now clear that analogous interactions occur in the supramolecular chemistry of metal-based compounds [64]. The focus of this section is to highlight direct interactions occurring between a given metal and an arene ring related to supramolecular association as opposed to "formal" $\eta^{5}$ coordination as found in, e.g. ferrocene. As mentioned in the Introduction, analogous formal ion $\cdots$ arene interactions, i.e. involving cations [65] and anions [66], are not covered herein.

\subsection{Metal $\cdots \pi($ arene $)$ interactions}

Metal $^{\cdots} \pi($ arene) interactions are long known to be important in materials science and biological process [67] and, increasingly, for their role in supramolecular chemistry. Most recent attention has been directed towards understanding the role of $\mathrm{Au}{ }^{*} \pi($ arene) interactions in the crystal chemistry of gold compounds. This interest relates directly to the great affinity of gold for $\pi$-systems [68a]. This attraction is so great that gold is described as being "carbophilic", a property that provides impetus to the burgeoning field in both homo- and hetero-geneous catalysis mediated by gold [68b-e].

A clue to the importance of supramolecular $\mathrm{Au}^{\cdots} \pi($ arene) interactions comes from the molecular structures of two polymorphs of $\left(\mathrm{Ph}_{2} \mathrm{PCH}_{2} \mathrm{PPh}_{2}\right)(\mathrm{AuCl})_{2}$. In the first reported form, Fig. 13a, the binuclear molecule, where the two gold atoms are linked by the bidentate bridging di-phosphane ligand, features an intramolecular $\mathrm{Au}^{\cdots} \mathrm{Au}$ interaction [69a]. More recently, a second form was described whereby an intramolecular $\mathrm{Au}^{\cdots} \pi($ arene) interaction is formed rather than the $\mathrm{Au}^{\cdots} \mathrm{Au}$ interaction [69b], Fig. 13b; there are no close intermolecular $\mathrm{Au}{ }^{\cdots} \mathrm{Au}$ interactions in either form. Given the energies differentiating polymorphs are inherently small [13], and that the energy of stabilisation provided by conventional hydrogen bonding and $\mathrm{Au}{ }^{\cdots} \mathrm{Au}$ interactions can be close [41], it follows $\mathrm{Au}^{\cdots} \pi($ arene) interactions must also provide 
similar levels of stabilisation to sustaining specific molecular conformations/intermolecular interactions. This assumption has been confirmed recently by computational chemistry where intramolecular $\mathrm{Au}{ }^{\cdots} \pi($ arene) interactions are reported to be $5-12 \mathrm{kcal} / \mathrm{mol}$ in several phosphanegold(I) thiolate molecules [70].

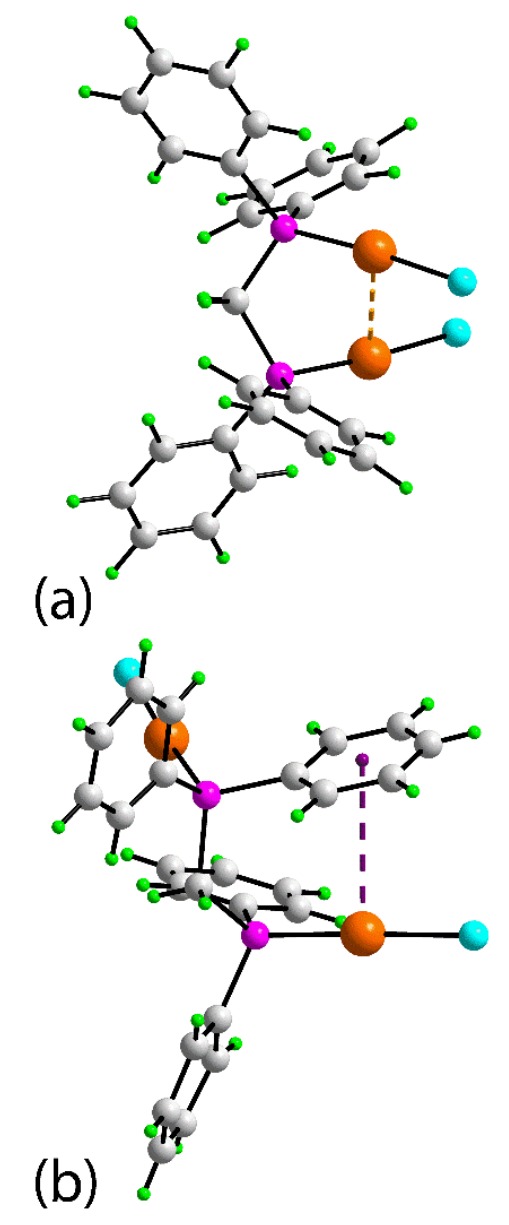

Figure 13. Molecular structures of polymorphs of $\left(\mathrm{Ph}_{2} \mathrm{PCH}_{2} \mathrm{PPh}_{2}\right)(\mathrm{AuCl})_{2}$ featuring intramolecular: (a) $\mathrm{Au}^{\cdots} \mathrm{Au}\left(3.34 \AA\right.$ ) $[69 \mathrm{a}]$ and (b) $\mathrm{Au}{ }^{\cdots} \pi$ (arene) $(3.58 \AA$ ) [69b] interactions. The purple dots in the arene rings represent the geometric ring centroids, and putative $\mathrm{Au} \cdots \mathrm{Cg}$ interactions are shown as purple dashed lines.

The supramolecular chemistry of $\mathrm{Au}^{\cdots}{ }^{\cdots} \pi($ arene) interactions has been surveyed in recent years [71] with the focus being upon delocalised interactions between gold and the arene ring 
[72], meaning the gold atom occupies a position nearly perpendicular to the ring and is approximately equidistant from the six carbon atoms comprising the ring. What follows is a brief description of some representative supramolecular assemblies based on $\mathrm{Au}^{\cdots} \pi($ arene) interactions, where zero- and one-dimensional aggregation patterns dominate, in an almost 1:1 ratio. In the molecular packing of $\left[\mathrm{MeN}(\mathrm{H}) \mathrm{C}(=\mathrm{O}) \mathrm{CH}_{2} \mathrm{CH}_{2}\right] \mathrm{Ph}_{2} \mathrm{PAuCl}$, Fig. 14a, two crystallographically independent molecules assemble via a single $\mathrm{Au}^{\cdots} \pi($ arene) interaction to form a dimeric aggregate [73a]. This is in fact quite rare, with the majority of dimeric aggregates assembling about a centre of inversion, forming two $\mathrm{Au}^{\cdots} \pi$ (arene) interactions. This is illustrated in Fig. 14b for dichlorido-(2-(dimethylaminomethyl)phenyl)gold(III) [73b] which also highlights that both gold(I), Fig. 14a, and gold(III) centres can form such interactions. Supramolecular chains are also found based on $\mathrm{Au}^{\cdots} \pi($ arene) interactions and can be of differing topology, e.g. linear, zig-zag and helical. An example of the latter is found in the crystal structure of $\mathrm{Ph}_{3} \mathrm{AsAuCl}$ [73c], Fig. 14c. 

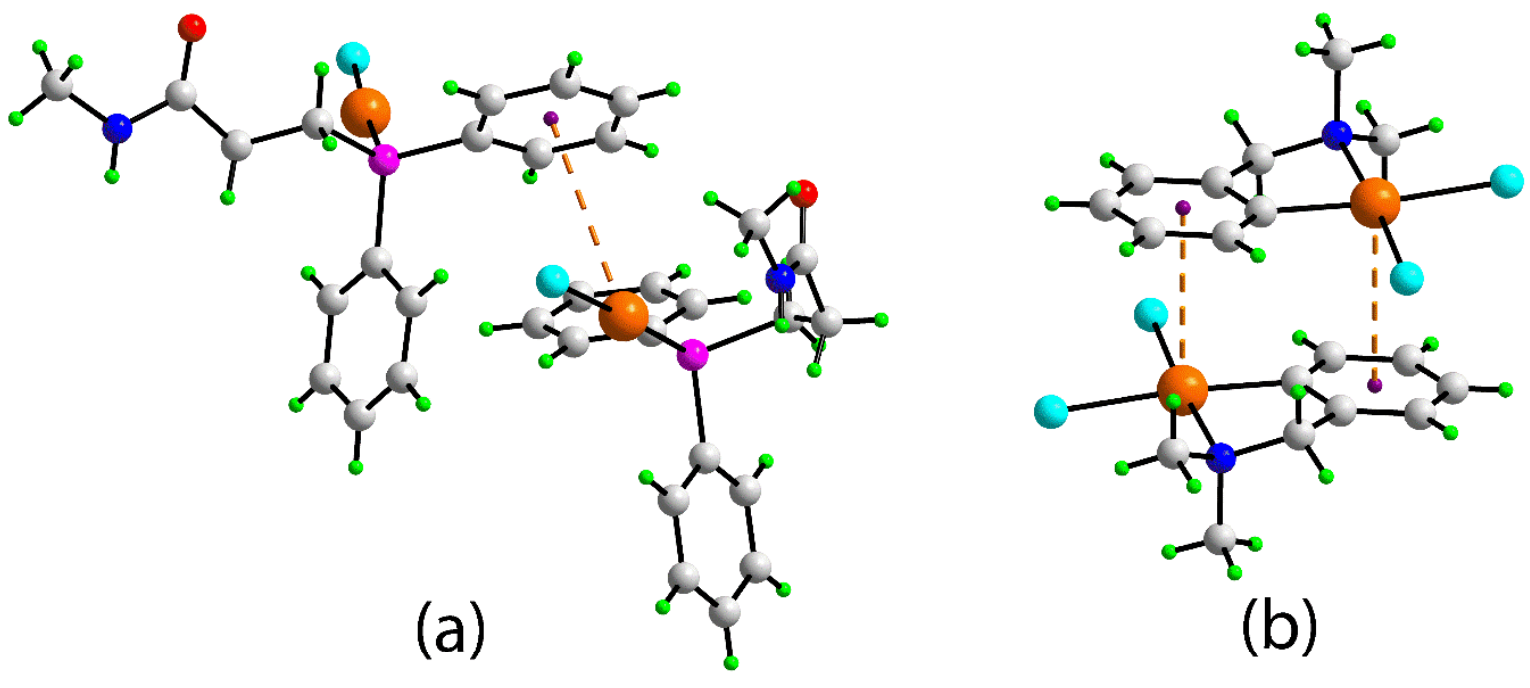

(b)

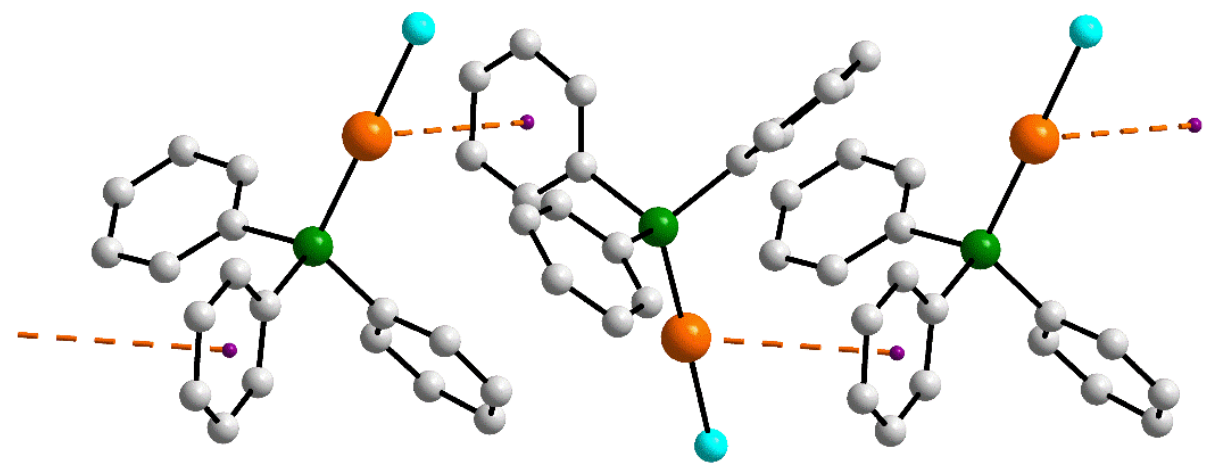

(c)

Figure 14. Illustrative examples of $\mathrm{Au}^{\cdots} \pi$ (arene) interactions leading to a: (a) dimeric aggregate in $\left[\mathrm{MeN}(\mathrm{H}) \mathrm{C}(=\mathrm{O}) \mathrm{CH}_{2} \mathrm{CH}_{2}\right] \mathrm{Ph}_{2} \mathrm{PAuCl}(3.92 \AA)$ [73a], (b) centrosymmetric dimeric aggregate in dichlorido-(2-(dimethylaminomethyl)phenyl)gold(III) (3.85 ^) [73b] and (c) helical supramolecular chain in $\mathrm{Ph}_{3} \mathrm{AsAuCl}(3.96 \AA$ ) [73c]. Additional colour code: arsenic, green.

\subsection{Metal(lone-pair) $\cdots \pi($ arene $)$ interactions}

The interaction between an electropositive metal centre and a $\pi$-system, as described in the preceding section, is readily explained in terms of conventional electrostatics. Less obvious are the interactions to be covered now, namely interactions between main group elements in lower oxidation states, implying the presence of a lone-pair(s) of electrons, and arene rings 
[74], i.e. Menschutkin complexes, exemplified by archetypal $\mathrm{SbCl}_{3} \cdot \mathrm{C}_{6} \mathrm{H}_{6}$. Contemporary theory provides an explanation in terms of the interaction of the $\pi$-electrons of the arene ring with the electropositive polar cap/ $\sigma$-hole $[16,21]$, located at the tip of the lone-pair, see Section 2.1. The possibility of a specific interaction between a lone-pair of electrons and an aromatic system was first raised in the context of macromolecular crystallography [75], and in the realm of the heavier main group elements, in discussions of tellurium stereochemistry [76].

Surveys over the past decade evaluating the role of metal(lone-pair) ${ }^{\cdots} \pi$ (arene) interactions, hereafter $\mathrm{M}(\mathrm{lp})^{\cdots} \pi($ arene $)$, in assembling main group element compounds in their crystals. Thus, bibliographic reviews are available for tin(II) [77a], lead(II) [77b], thallium(I) [77c], arsenic(III) [77d], antimony(III) [77e], bismuth(III) [77e], selenium(II, IV) [77f,g] and tellurium(II, IV) [77g-i] with both an overview [77j] and update for all cited elements [77k] published during 2016. In these studies, evidence was sought for delocalised $\mathrm{M}(\mathrm{lp}){ }^{\cdots} \pi($ arene$)$ interactions operating in isolation of complementary interactions such as hydrogen bonding and secondary bonding. From this wealth of data, a few illustrative examples are presented now.

Supramolecular association sustained by $\mathrm{M}(\mathrm{lp}) \cdots \pi($ arene) interactions usually lead to zero- and one-dimensional aggregation patterns. Far less common are two-dimensional assembly based on $\mathrm{M}(\mathrm{lp})^{\cdots} \pi($ arene) interactions with only a few examples of three-dimensional architectures. A zero-dimensional species is found in the crystal structure of $\{$ hydrogen tris[4bromo-3-(p-chlorophenyl)pyrazolyl]borato\}thallium(I) chlorobenzene solvate [78a] which features a $\operatorname{Tl}(\mathrm{lp})^{\cdots} \pi($ arene) interaction between the pyramidal thallium(I) centre and the $\pi$ system of the solvent molecule, Fig. 15a. While single $\mathrm{M}(\mathrm{lp})^{\cdots} \pi($ arene) interactions between a complex molecule and solvent, and between disparate, i.e. crystallographically independent, molecules are seen, the overwhelming majority of zero-dimensional aggregate see two likemolecules connected about a centre of inversion. An example of this common structural motif 
is shown in Fig. $15 \mathrm{~b}$, i.e. for chlorido-(diphenyl- $\beta$-diketiminato)tin(II) [78b], also with a pyramidal coordination geometry about the tin(II) centre. However, more exotic zerodimensional aggregates are also known as in the trinuclear aggregate found in the molecular packing of (2.2.2)paracyclophane tris[trichloridobismuth(III)] benzene solvate [78c], Fig. 15c, and in the centrosymmetric, tetranuclear aggregate found in the structure of 1,2-diphenylethyne tetrakis[trichloridoantimony(III)] [78d], Fig. 15d.

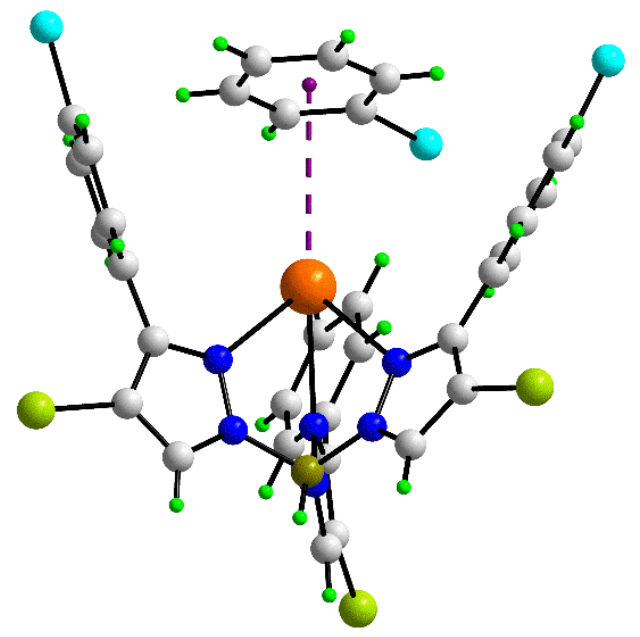

(a)

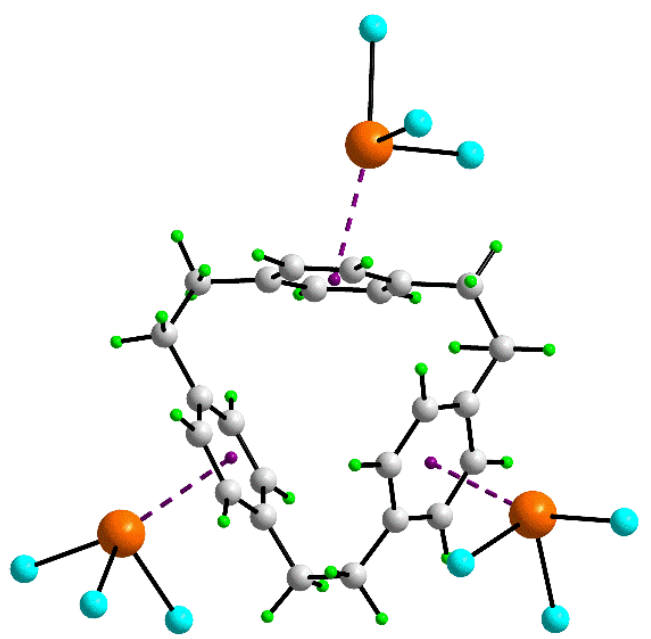

(c)

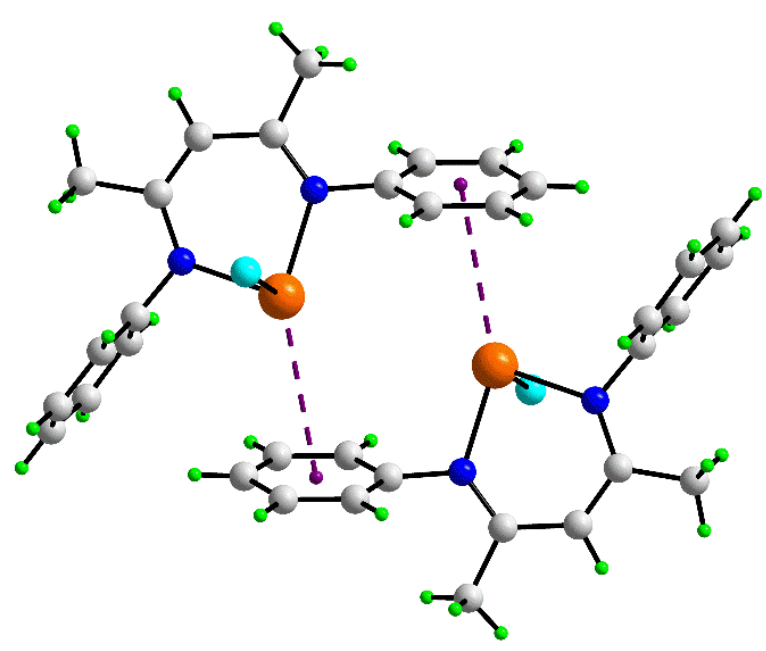

(b)

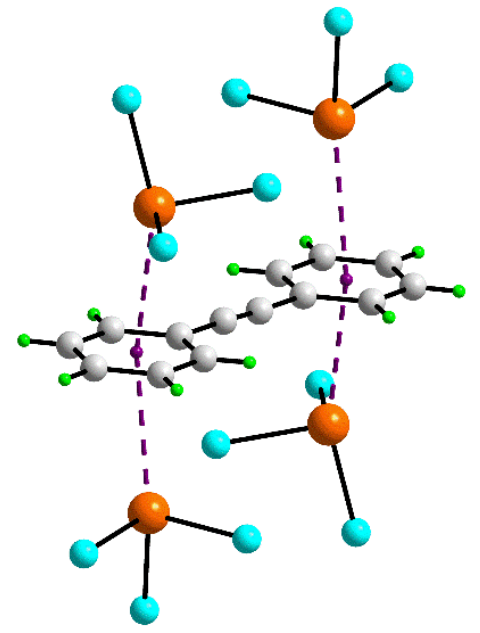

(d)

Figure 15. Zero-dimensional aggregates sustained by $M(\operatorname{lp})^{\cdots} \pi($ arene) interactions (shown as purple dashed lines):

(a) \{hydrogen tris[4-bromo-3-(p- 
chlorophenyl)pyrazolyl]borato thallium(I) chlorobenzene solvate $\left(\mathrm{Tl} \cdots \mathrm{Cg}=3.69 \AA, \alpha=14.5^{\circ}\right)$ [78a], (b) chlorido-(diphenyl- $\beta$-diketiminato)tin(II) $\left(\mathrm{Sn} \cdots \mathrm{Cg}=3.69 \AA, \alpha=14.5^{\circ}\right)[78 \mathrm{~b}]$, (c)

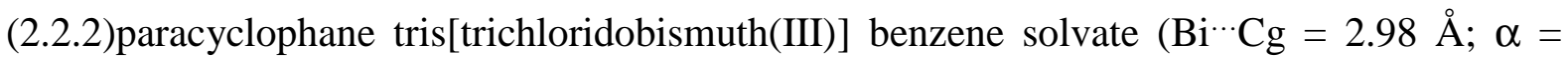
$10.5^{\circ} ; \mathrm{d}=2.99 \AA ; \alpha=5.6^{\circ}$ and $3.08 \AA$ and $3.5^{\circ}$ second and third independent contacts) [78c] and (d) centrosymmetric 1,2-diphenylethyne tetrakis[trichloridoantimony(III)] ( $\mathrm{Sb} \cdots \mathrm{Cg}=3.28$ $\AA, \alpha=6.6^{\circ} ; 3.39 \AA$ and $9.2^{\circ}$ for independent second contact) [78d]. The angle $\alpha$ represent the angle between the vector perpendicular to the plane through the arene ring and that between the ring centroid and the main group element, M. Additional colour code: bromide; lime.

Illustrative examples of $\mathrm{M}(\mathrm{lp}) \cdots \pi($ arene) interactions leading to one-dimensional aggregation are shown in Fig. 16. The supramolecular chain in chlorido-(toluene-3,4dithiolato)arsenic(III) [79a], Fig. 16a, is truly remarkable in that rather than forming more conventional $\mathrm{As}^{\cdots} \mathrm{Cl}$ and $\mathrm{As}{ }^{\cdots} \mathrm{S}$ secondary (pnictogen) bonding interactions, there are none in any dimension of the molecular packing, a As(lp) ${ }^{\cdots} \pi($ arene) interaction being formed instead. Such an observation suggests the energy of stabilisation of a As(lp) ${ }^{\cdots} \pi($ arene $)$ interaction might be comparable to the energy of stabilisation afforded by a putative secondary $\mathrm{As}{ }^{\cdots} \mathrm{Cl}$ and $\mathrm{As}{ }^{\cdots} \mathrm{S}$ secondary bonding interaction. In the crystal of the highly symmetric (crystallographic mmm symmetry) tetradeca-bismuth(III) compound shown in Fig. 16b, two distinct solvent benzene molecules interact with the cluster. Four form a single interaction to a bismuth(III) atom while two others bridge two bismuth(III) centres leading to a supramolecular chain [79b]. An example where each repeat unit participates in four $\mathrm{Te}(\mathrm{lp})^{\cdots} \pi($ arene) interactions leading to a linear supramolecular chain is evident in centrosymmetric trans-1,2-dichlorido-1,2bis(phenyltellanyl)ethylene [79c], Fig. 16c. Indeed, supramolecular chains of various topologies are found for all of the main group elements and these can be sustained by single or multiple metal(lp) $\cdots \pi($ arene) interactions [77]. 

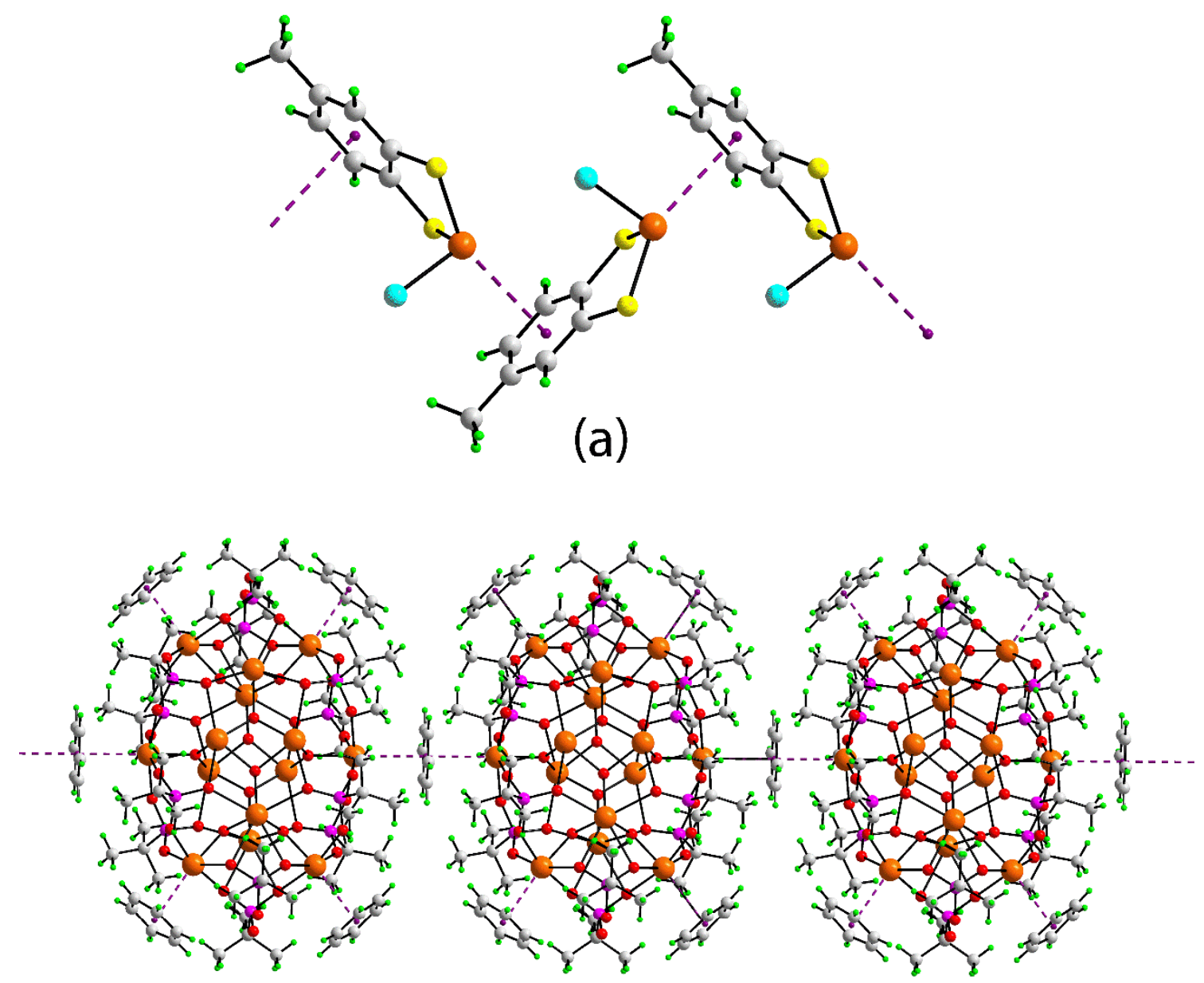

(b)

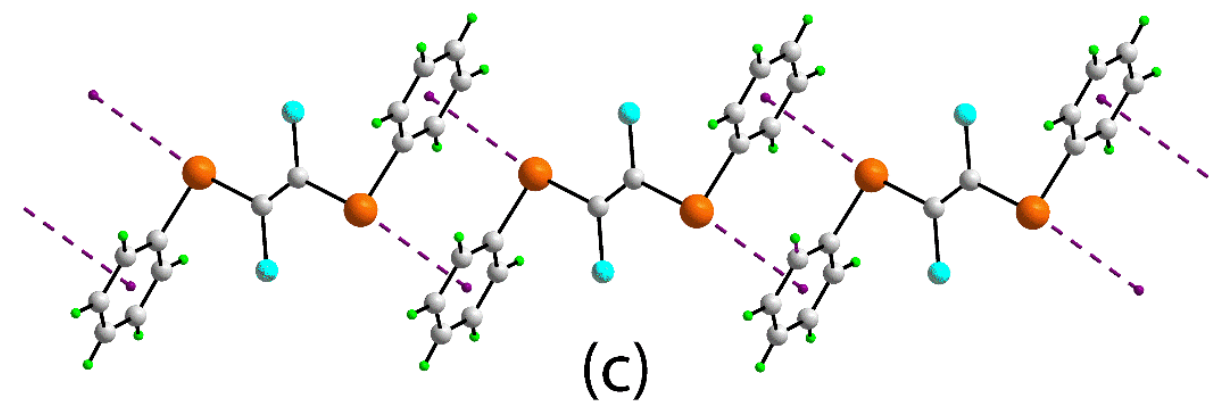

Figure 16. One-dimensional aggregates sustained by $\mathrm{M}(\mathrm{lp}) \cdots \pi($ arene) interactions: (a) chlorido-(toluene-3,4-dithiolato)arsenic(III) (As $\left.{ }^{\cdots} \mathrm{Cg}=3.30 \AA, \alpha=3.6^{\circ}\right)$ [79a], (b) hexakis $\left(\mu_{4-}\right.$ t-butylphosphonato)-bis( $\mu_{4}$-t-butylhydrogenphosphonato)-decakis $\left(\mu_{3}\right.$-oxido)-tetrakis $\left(\mu_{3}\right.$-tbutylphosphonato)-tetradeca-bismuth(III) benzene solvate tetrahydrate (Bi $\cdots \mathrm{Cg}=3.19 \AA$, $\alpha=$ $0.0^{\circ}$ (bridging benzene); $\mathrm{d}=3.21 \AA, \alpha=5.8^{\circ}$ ) [79b] and (c) trans-1,2-dichlorido-1,2- 
bis(phenyltellanyl)ethylene $\left(\mathrm{Te}{ }^{\cdots} \mathrm{Cg}=3.93 \AA, \alpha=19.1^{\circ}\right)$ [79c]. Non-participating entities are omitted from (b).

An example of two-dimensional aggregation sustained by $\operatorname{Se}(\mathrm{lp}) \cdots \pi($ arene) interactions is found in the molecular packing of 1,2,4,5-tetrafluorido-3,6-bis(phenylseleno)benzene [80], Fig. 17. Here, the molecule is centrosymmetic and participates in four $\operatorname{Se}(\operatorname{lp})^{\cdots} \pi(\operatorname{arene})$ interactions that extend laterally to form a layer.

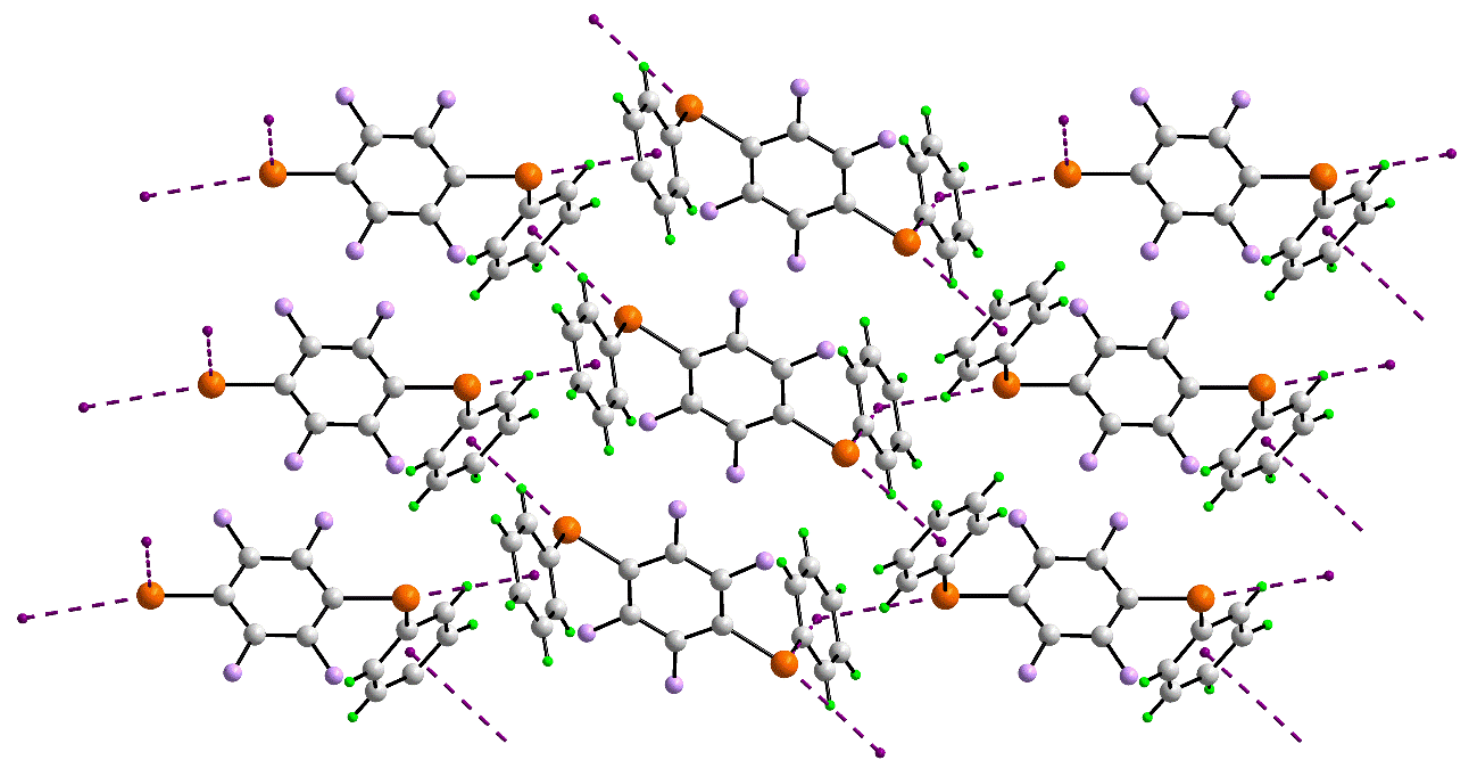

Figure 17. Two-dimensional aggregation sustained by $\operatorname{Se}(\mathrm{lp}) \cdots \pi($ arene) interactions in the molecular packing of 1,2,4,5-tetrafluorido-3,6-bis(phenylseleno)benzene ( $\mathrm{As} \cdots \mathrm{Cg}=3.68 \AA$, $\alpha$ $=8.8^{\circ} ; 3.88 \AA$ and $18.7^{\circ}$ for second contact) [80].

As suggested in Section 3.4, attempts at correlating weak interactions with systematic changes in chemistry are not recommended, at least based on experimental, i.e. crystallographic, results. However, increasing attention by theoreticians reveal systematic variations in $\mathrm{M} \cdots$ ring centroid distances that correlate the electronic properties of the participating species [80]. With reference to the classical $\mathrm{SbCl}_{3} \cdot \mathrm{C}_{6} \mathrm{H}_{6}$ aggregate, the addition 
of methyl groups significantly enhances the interaction energy, from ca 8 to $10 \mathrm{kcal} / \mathrm{mol}$, and permethylation increases the energy to $16 \mathrm{kcal} / \mathrm{mol}$ [81a]. These energies approach, even exceed, those observed for hydrogen bonding and, again, a very recent study on a pair of tautomeric structures suggests intramolecular oxygen(lone-pair) $\cdots \pi$ (carbonyl) interactions are competitive with intramolecular $\mathrm{O}-\mathrm{H}^{\cdots} \mathrm{O}$ hydrogen bonding [81c]. These sorts of advances suggest that further effort in this aspect of supramolecular chemistry is desirable.

\section{Interactions involving chelate rings}

The concept of metalloaromaticity or chelatoaromaticity [82], i.e. chelate rings that have aromatic character, remains controversial and the subject of experimental and theoretical investigations [83]; also see Section 7. Nevertheless, there is a growing body of evidence to show that chelate rings can assemble much in the same way as, for example, arene rings. Thus, in the following, examples of chelate rings interacting with arene rings, chelate rings with chelate rings, and chelate rings accepting carbon-bound hydrogen atoms will be presented.

Stacking interactions involving chelate and arene rings have emerged as being important supramolecular synthons over the last decade, especially for sterically unencumbered square planar, transition metal complexes [84]. Based on systematic literature surveys of square-planar metal complexes, the off-set, face-to-face interactions often formed between a chelate ring and a $\pi$-system resembles the classical benzene dimer [84], suggesting that chelate rings can associate in a similar fashion as arene rings [84a]. Preferential formation of $\pi$ (chelate $)^{\cdots} \pi($ arene $)$ over $\pi(\text { arene })^{\cdots} \pi($ arene $)$ interactions, at least having closer intercentroid separations, is indicated for square-planar complexes having an arene ring fused to a chelate ring [84b]. Emphasising this last point, in the illustrated example highlighting the formation of $\pi$ (chelate) $\cdots \pi($ arene $)$ interactions in the crystal of bis(acetone-1- 
naphthoylhydrazinato)copper(II) [85], Fig. 18a, the centrosymmetric molecules are connected into a linear chain via $\pi\left(\mathrm{CuCN}_{2} \mathrm{O}\right) \cdots \pi($ arene $)$ interactions.

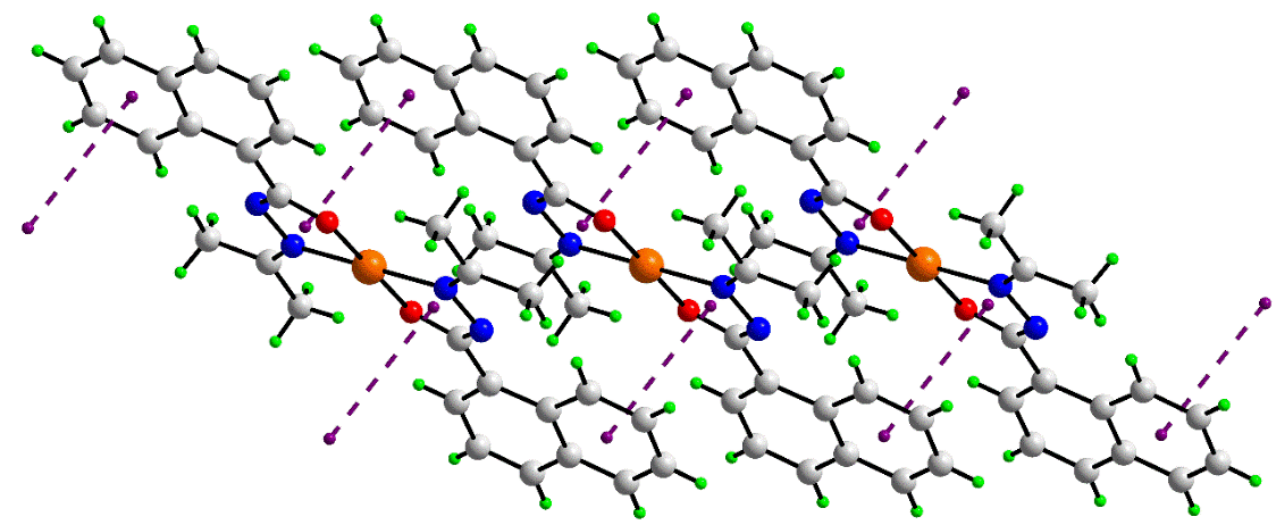

(a)

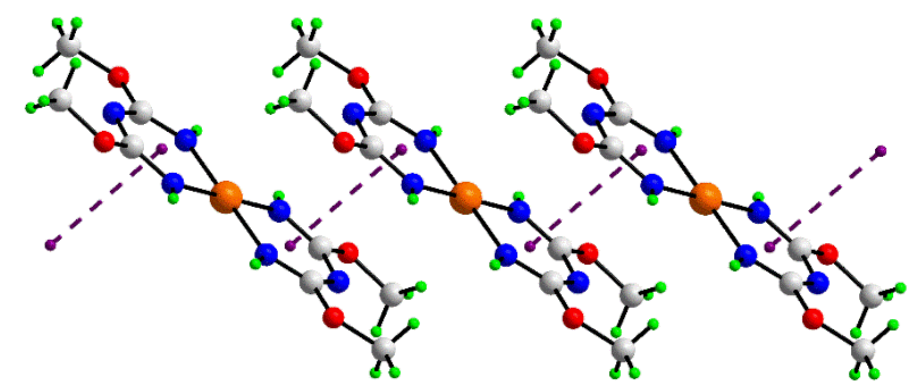

(b)

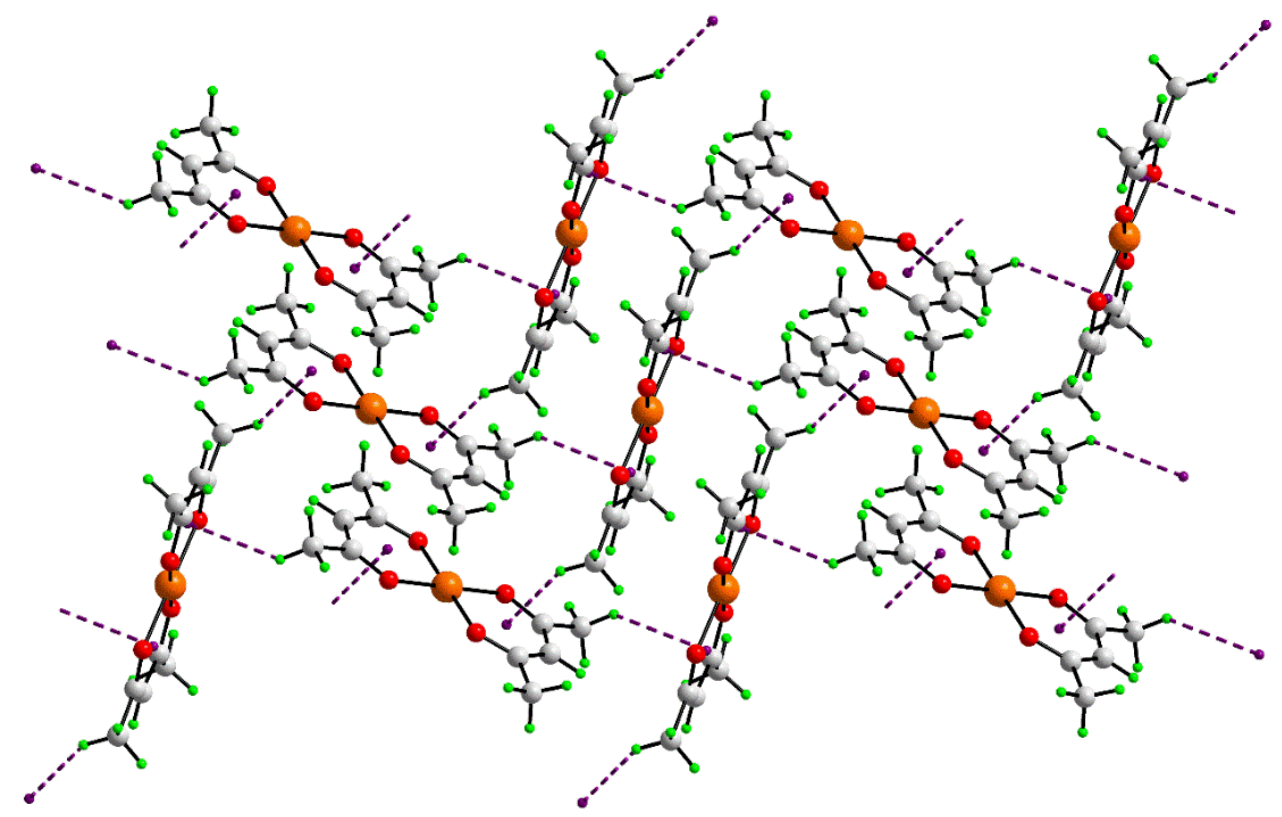

(c) 
Figure 18. Supramolecular aggregation mediated by interactions involving chelate rings: (a) chain sustained by $\pi$ (chelate) $\cdots \pi($ arene $)$ interactions in bis(acetone-1naphthoylhydrazinato)copper(II) $\left(\mathrm{Cg} \cdots \mathrm{Cg}=3.70 \AA \begin{array}{l}\AA \\ )\end{array}\right.$ [85], (b) chain sustained by $\pi($ chelate $) \cdots($ chelate $) \quad$ interactions $\quad$ in $\quad$ centrosymmetric bis[bis(methoxycarbimido)aminato]copper(II) $\quad(\mathrm{Cg} \cdots \mathrm{Cg}=3.70 \AA ̊$ ) [87] and (c) twodimensional array sustained by $\mathrm{C}-\mathrm{H}^{\cdots} \pi($ chelate $)$ interactions in $\operatorname{bis}(2,4-$ pentanedionato)palladium(II) $\left(\mathrm{C}-\mathrm{H}^{\cdots} \mathrm{Cg}=3.18 \AA\right.$, angle at $\left.\mathrm{H}=139^{\circ}\right)$ [90].

A logical extension in these investigations is an analysis for $\pi$ (chelate) ${ }^{\cdots} \pi$ (chelate) interactions and, indeed, these occur in nearly $39 \%$ of neutral, transition metal square-planar complexes [86]. As a comprehensive review of this topic is given in a companion article [86b], comments are kept to a minimum in this section, it suffices to mention that $\pi$ (chelate) $\cdots \pi$ (chelate) interactions have the hallmarks of their all-organic analogues. An example illustrating $\pi$ (chelate) $\cdots \pi$ (chelate) interactions is found in the structure of centrosymmetric bis[bis(methoxycarbimido)aminato]copper(II) [87]. Here, five-membered $\left(\mathrm{CuCN}_{2} \mathrm{O}\right)$ chelate rings associate in a stacked manner to form a supramolecular chain. Computational chemistry estimates that the energy of attraction between pairs of rings in this supramolecular arrangement amounts to ca $8 \mathrm{kcal} / \mathrm{mol}[87 \mathrm{~d}]$.

In keeping with the steric hindrance arguments in Sections 2.3 and 3.2, stacking interactions involving chelate rings are precluded when the substituents are large with the consequence that $\mathrm{C}-\mathrm{H}^{\cdots} \pi$ (chelate) interactions are more likely to form [88]. Indeed, a significantly greater number of investigations have been dedicated to $\mathrm{C}-\mathrm{H}^{\cdots} \pi$ (chelate) interactions cf. other interactions involving chelate rings. An early, specific reference to the possibility of $\mathrm{C}-\mathrm{H}^{\cdots} \pi$ (chelate) interactions stabilising a crystal structure was for bi-pyridyl adducts of cadmium bis(xanthate) compounds [89a] and these along with other 1,1-dithiolate 
complexes, e.g. containing dithiocarbamates, have arguably attracted the most attention in this area [89]. This observation notwithstanding, $\mathrm{C}-\mathrm{H}^{\cdots} \pi$ (chelate) interactions have also been evaluated in complexes of acetylacetonates [90a,b], porphyrins [90c] and di-imines [90d]. An illustration of a two-dimensional architecture stabilised by methyl-C- $\mathrm{H}^{\cdots} \pi$ (chelate) interactions is found in the molecular packing of centrosymmetric bis(2,4pentanedionato)palladium(II) [91], Fig. 18c. A subsequent computational study [90b] suggests a binding energy to the aromatic chelate $\left(\mathrm{PdC}_{3} \mathrm{O}_{2}\right)$ ring of $4-5 \mathrm{kcal} / \mathrm{mol}$.

A series of 12 binary palladium xanthates, i.e. $\left[\mathrm{Pd}\left(\mathrm{S}_{2} \mathrm{COR}\right)_{2}\right]$, was reported recently with $\mathrm{Pd}^{\cdots} \mathrm{S}$ interactions observed with smaller $\mathrm{R}$ groups being steadily replaced by $\mathrm{C}-$ $\mathrm{H}^{\cdots} \pi$ (chelate) interactions as the bulk of the R groups were increased [89d]. Calculations in this study suggested higher energies of stabilisation, cf. bis(2,4-pentanedionato)palladium(II) [90b], i.e. ca $15 \mathrm{kcal} / \mathrm{mol}$ for the $\mathrm{R}=\mathrm{n}-\mathrm{Pr}$ compound, an energy only slightly less than that afforded by a complementary $\mathrm{Pd} \cdots \mathrm{S}$ interaction. Clearly, from the foregoing, there is enormous scope for further work in this area.

\section{Interactions involving quasi-chelate rings}

It was highlighted in Section 6.1 that the electronic nature, i.e. the aromaticity, of chelate rings is still the subject of debate. This may in fact be a moot point in consideration of the supramolecular association to be described in this section. There is mounting evidence that rings mediated by hydrogen bonding, i.e. where a formal covalent bond in a chelate ring is replaced by a hydrogen bond, leading to a quasi-chelate ring, can participate in attractive intermolecular interactions and that these rings need not necessarily be aromatic [92]. For example, there is an indication that stacking interactions between hydrogen-bonded rings are stronger than those formed by benzene molecules [93]. Recently, evidence was reported for the formation of $\mathrm{C}-\mathrm{H}^{\cdots}$ (quasi-chelate) interactions [94]. 
A C- $\mathrm{H}^{\cdots}$ (quasi-chelate) interaction was first noted intramolecularly in the structure of $\left(\mathrm{Ph}_{3} \mathrm{P}\right)_{2} \mathrm{Cu}[\mathrm{S}=\mathrm{C}(\mathrm{OEt})=\mathrm{N}(\mathrm{H}) \mathrm{Ph}] \mathrm{Cl}$, which features a six-membered $\{\cdots \mathrm{ClCuSCNH}\}$ quasichelate ring [94a]. Computational chemistry indicated the ring was non-aromatic and the attractive interaction amounted to $3.5 \mathrm{kcal} / \mathrm{mol}$ [94a]. A literature survey indicated approximately $1 / 6$ of structures having a $\{\cdots \mathrm{ClCuSCNH}\}$ quasi-chelate ring, formed a $\mathrm{C}-$ $\mathrm{H}^{\cdots}$ (quasi-chelate) interaction. Attention was next directed to the formation of related intermolecular $\mathrm{C}-\mathrm{H}^{\cdots}$ (quasi-chelate) interactions, i.e. intermolecular $\mathrm{C}-\mathrm{H}^{\cdots}(\mathrm{ClCuSCNH})$ interactions [94b]. Zero-, one- and two-dimensional aggregation patterns sustained by these interactions were discovered. Exemplars are shown in Fig. 19. A zero-dimensional aggregate sustained by a single interaction between two crystallographically independent molecules is found in the molecular packing of chlorido-bis(isopropylimidazolidine-2-thione)copper(I) [95a], Fig. 19a. Interestingly, only one of the identified structures assembled into a zerodimensional aggregate, there been an almost split between one- and two-dimensional aggregation patterns. An example of the former is found in the structure of chlorido-bis(1,3thiazolidine-2-thione)copper(I) [95a], which is 2-fold symmetric and forms two $\{\cdots \mathrm{ClCuSCNH}\}$ quasi-chelate rings, each of which participates in a methylene-C-H $\cdots$ (quasichelate) interaction leading to a twisted supramolecular chain as shown in Fig. 19b. An example of two-dimensional aggregation is seen in the crystal of centrosymmetric and binuclear bis( $\mu_{2}$-3-methyl-1,3-dihydro-2H-imidazole-2-thione)-dichlorido-bis(3-methyl-1, 3dihydro-2H-imidazole-2-thione)-di-copper(I) [95b]. Unlike the preceding examples with trigonal planar coordination geometries for copper(I), in this structure, a tetrahedral geometry based on a $\mathrm{ClS}_{3}$ donor set is found. Only two of the quasi-chelate rings participate in imidazolyl-C-H $\mathrm{H}^{\cdots}$ (quasi-chelate) interaction, extending laterally to form the two-dimensional framework, Fig. 19c. 

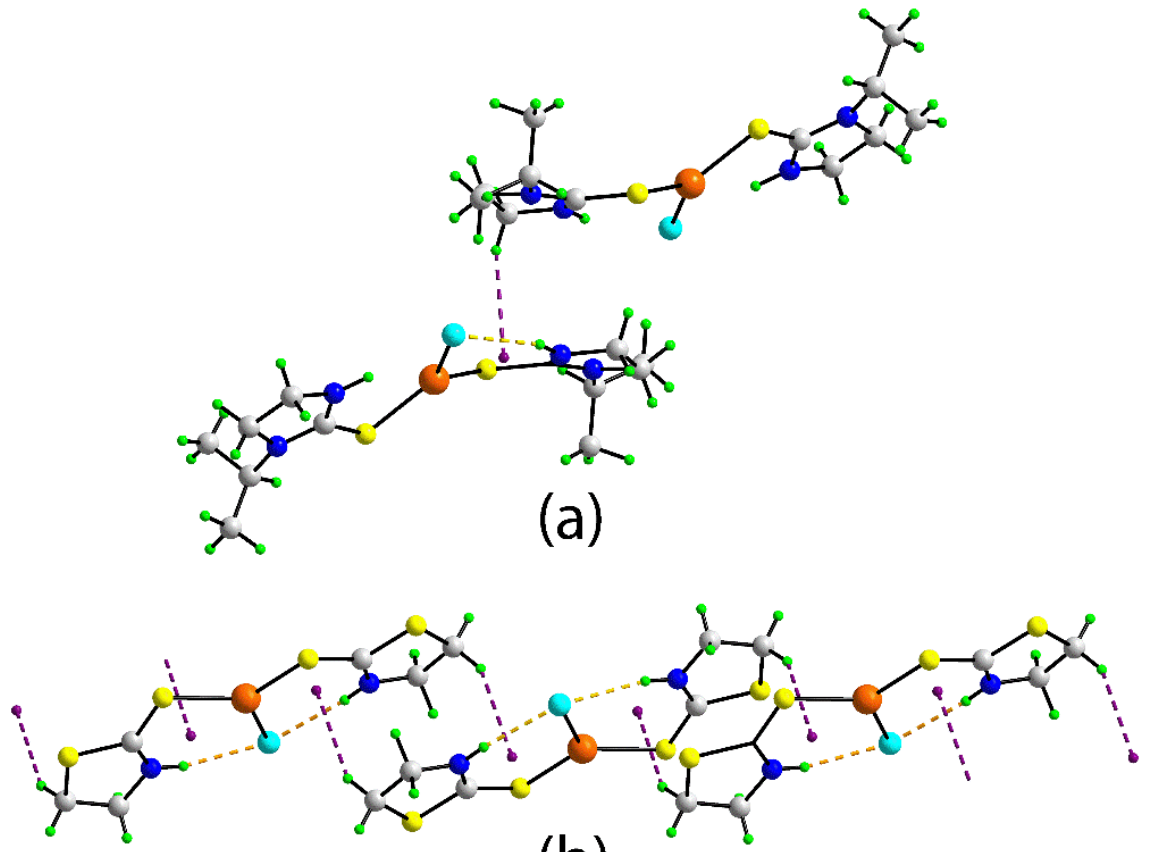

(b)

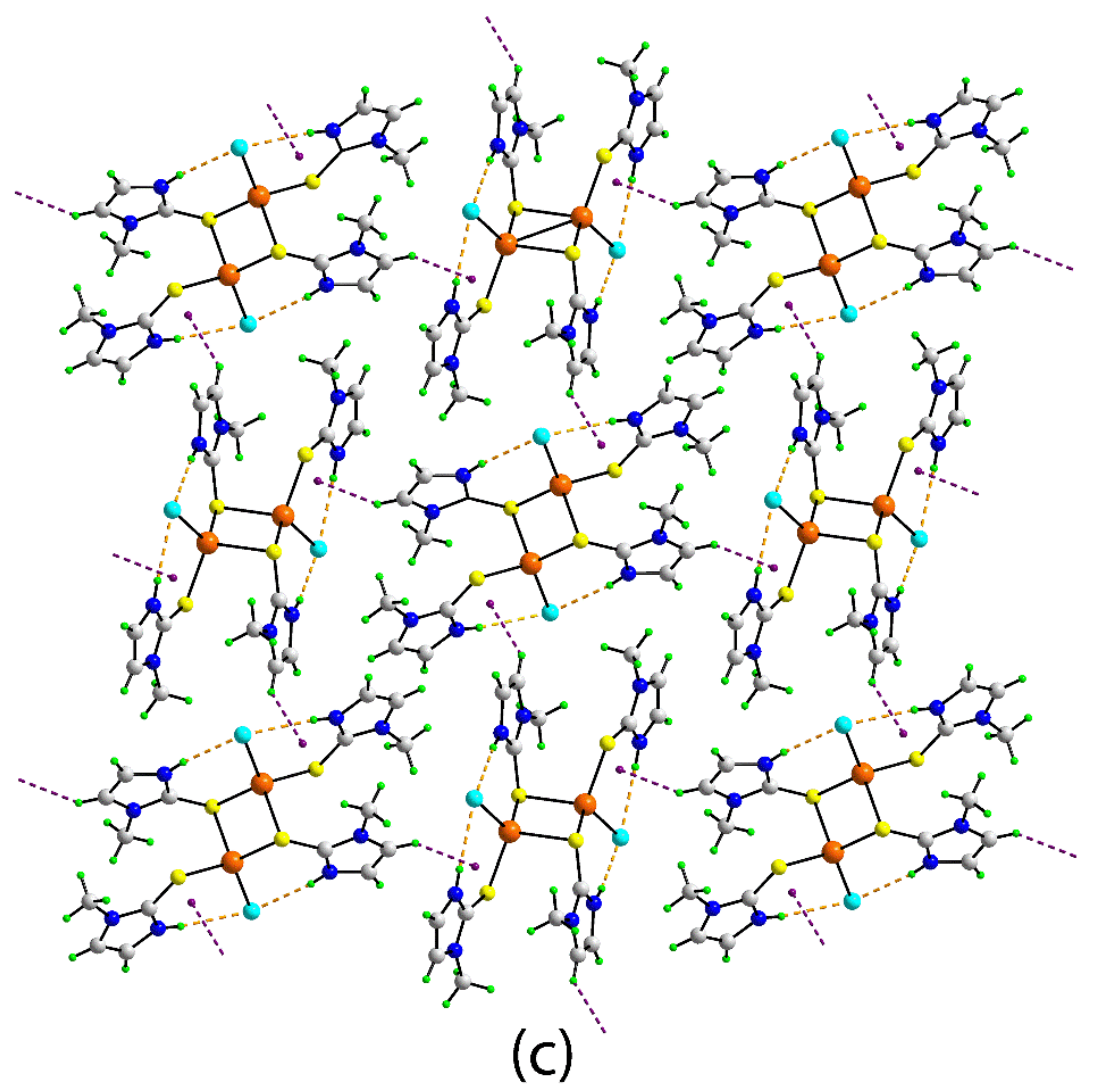

Figure 19. Supramolecular aggregation mediated by $\mathrm{C}-\mathrm{H}^{\cdots} \pi$ (quasi-chelate) interactions: (a) a non-symmetric dimer in chlorido-bis( $\mathrm{N}$-isopropylimidazolidine-2-thione)copper(I) $\left(\mathrm{C}-\mathrm{H}{ }^{\cdots} \mathrm{Cg}\right.$ $=2.78 \AA$, angle at $\mathrm{H}=147^{\circ}$ ) [95a], (b) a supramolecular chain in chlorido-bis(1,3-thiazolidine- 
2-thione $)$ copper(I) $\left(\mathrm{C}-\mathrm{H}^{\cdots} \mathrm{Cg}=2.72 \AA\right.$, angle at $\left.\mathrm{H}=151^{\circ}\right)$ [95b] and (c) a two-dimensional framework in bis( $\mu_{2}-3$-methyl-1,3-dihydro-2H-imidazole-2-thione)-dichlorido-bis(3-methyl1, 3-dihydro-2H-imidazole-2-thione)-di-copper(I) $\left(\mathrm{C}-\mathrm{H}^{\cdots} \mathrm{Cg}=2.35 \AA\right.$, angle at $\left.\mathrm{H}=141^{\circ}\right)$ [95c]. The intramolecular $\mathrm{N}-\mathrm{H}^{\cdots} \mathrm{Cl}$ hydrogen bonds are shown as orange dashed lines.

In all, there are approximately 90 structures in the crystallographic literature capable of forming $\{\cdots \mathrm{ClCuSCNH}\}$ quasi-chelate rings and, of these, about one-third form $\mathrm{C}-\mathrm{H}^{\cdots}$ (quasichelate) interactions in their solid-state structures, either intra- or inter-molecularly. It is noteworthy that this percentage matches the formation of the eight-membered carboxylic acid dimer synthon, i.e. $\{\cdots \mathrm{HOCO}\}_{2}[96]$, often cited as being an important supramolecular synthon is crystal engineering.

\section{Conclusions}

The foregoing presents an overview of the different types of supramolecular associations that can specifically operate in the crystal structures of heavy element compounds of the transition metals and main group elements, and beyond. These interactions may be secondary in nature, now classified as tetrel, pnicotgen and chalcogen bonding interactions, depending on the interacting elements. These are rationalised in terms of electropositive polar caps on lone-pairs of electrons which interact with electron-rich regions. Interactions can occur directly between metal centres with like or unlike metals, offering opportunities for tailoring specific photoluminescent responses. Direct connections between a metal and hydrogen, i.e. $\mathrm{M} \cdots \mathrm{H}$ bonding, are also known. Metals can also associate with $\pi($ arene) rings to form recognisable supramolecular aggregates and using similar arguments concerning polar caps on lone-pairs of electrons, main group element(lone-pair) $\cdots \pi$-interactions are now recognised in sustaining supramolecular aggregation patterns. $\pi$-Systems based on chelate rings can also 
assemble as do their all-organic counterparts, i.e. participating in $\pi$ (chelate) $\cdots \pi($ arene), $\pi$ (chelate) $\cdots \pi($ chelate $)$ and $\mathrm{C}-\mathrm{H}^{\cdots} \pi$ (chelate) contacts. Finally, proving metal-aromaticity is not the sole criterion for supramolecular assembly based on chelate rings, quasi-chelate rings mediated by hydrogen bonding can also participate in $\mathrm{C}-\mathrm{H}^{\cdots}$ (pseudo-chelate ring) interactions.

The role of computational chemistry in rationalising the formation of the cited intermolecular interactions cannot be underestimated, both in terms of explaining, for example, why seemingly two negatively charged entities can form attractive interactions, and by providing estimates of the energies of stabilisation provided by specific interactions. Interestingly, many of the just-mentioned attractive intermolecular interactions, often involving atoms/residues at the periphery of molecules, provide energies of stabilisation approaching those afforded by conventional hydrogen bonding. This suggests the possible utility of these "emerging" interactions in crystal engineering enterprises. Whatever the motivations for their study, continued advances in our understanding of the supramolecular associations specific to the coordination chemist, can only contribute to a general understanding of how and why molecules assemble as they do in the solid-state, surely, the crucial question in molecular crystallography.

\section{Acknowledgements}

The support of Skim Geran Penyelidikan Trans-Displin (TRGS; TR002-2014A), Malaysia, is gratefully acknowledged. 


\section{References}

[1] B.F. Hoskins, R. Robson, J. Am. Chem. Soc. 112 (1990) 1546.

[2] B. Moulton, M.J. Zaworotko, Chem. Rev. 101 (2001) 1629; A.J. Howarth, Y.Y. Liu, P. Li, Z.Y. Li, T.C. Wang, J. Hupp, O.K. Farha, Nat. Rev. Mat. 1 (2016) 15018.

[3] S.L. James, Chem. Soc. Rev. 32 (2003) 276; C.N.R. Rao, S. Natarajan, R. Vaidhyanathan, Angew. Chem. Int. Ed. 43 (2004) 1466; S. Kitagawa, R. Kitaura, S.-I. Noro, Angew. Chem. Int. Ed. 43 (2004) 2334; G. Férey, Chem. Soc. Rev. 37 (2008) 191; (e) W.L. Leong, J.J. Vittal, Chem. Rev. 111 (2011) 688; H. Furukawa, K.E. Cordova, M. O'Keeffe, O.M. Yaghi, Science, 341 (2013) art. no. 123044; H.-C. Zhou, S. Kitagawa, Chem. Soc. Rev. 43 (2014) 5415.

[4] B.Y. Li, M. Chrzanowski, Y.M. Zhang, S.Q. Ma, Coord. Chem. Rev. 307 (2016) 106; B. Seoane, S. Castellanos, A. Dikhtiarenko, F. Kapteijn, J. Gascon, Coord. Chem. Rev. 307 (2016) 147; Y.J. Cui, B. Li, H. J. He, W. Zhou, B.L. Chen, G.D. Qian, Acc. Chem. Res. 49 (2016) 483; M.H. Sun, S.Z. Huang, L.H. Chen, Y. Li, X.Y. Yang, Z.Y. Yuan, B.L. Su, Chem. Soc. Rev. 45 (2016) 3479; C.H. Wang, X.L. Liu, N.K. Demir, J.P. Chen, K. Li, Chem. Soc. Rev. 45 (2016) 5107.

[5] C. He, D. Liu, W. Lin, Chem. Rev. 115 (2015) 11079; M. Gimenez-Marques, T. Hidalgo, C. Serre, P. Horcajada, Coord. Chem. Rev. 307 (2016) 342.

[6] (a) Y. Belmabkhout, V. Guillerm, M. Eddaoudi, Chem. Eng. J. 296 (2016) 386; (b) P. Kumar, K.H. Kim, E.E. Kwon, J.E. Szulejko, J. Mat. Chem. A 4 (2016) 345; (c) R.B. Lin, S.Y. Liu, J.W. Ye, X.Y. Li, J.P. Zhang, Adv. Sci. 3 (2016) art. no. 1500434; (d) Y.Y. Zhang, X. Feng, S. Yuan, J.W. Zhou, B. Wang, Inorg. Chem. Front. 3 (2016) 896; (e) R. Kaur, K.H. Kim, A.K. Paul, A. Deep, J. Mat. Chem. A 11 (2016) 3991; (f) C.L. Jones, A. Tansell, T.L. Easun, J. Mat. Chem. A 4 (2016) 6714; (g) T.H. Noh, O.S. Jung, Acc. Chem. Res. 49 (2016) 1835; (h) L.R. Mingabudinova, V.V. Vinogradov, V.A. 
Milichko, E. Hey-Hawkins, A.V. Vinogradov, Chem. Soc. Rev. 45 (2016) 5408; (i) L. Sun, M.G. Campbell, M. Dinca, Angew. Chem. Int. Ed. 55 (2016) 3566; (j) L. Wang, Y.Z. Han, X. Feng, J.W. Zhou, P.F. Qi, B. Wang, Coord. Chem. Rev. 307 (2016) 361; (k) S. Zhang, Q. Yang, X.Y. Liu, X.N. Qu, Q. Wei, G. Xie, S.P. Chen, S.L. Gao, Coord. Chem. Rev. 307 (2016) 292; (1) J. Aguilera-Sigalat, D. Bradshaw, Coord. Chem. Rev. 307 (2016) 267; (m) C.R. Kim, T. Uemura, S. Kitagawa, Chem. Soc. Rev. 45 (2016) 3828; (n) J. Jiang, Y. Zhao, O.M. Yaghi, J. Am. Chem. Soc. 138 (2016) 3255; (o) A. Ayati, M.N. Shahrak, B. Tanhaei, M. Sillanpaa, Chemosphere 160 (2016) 30; (p) I. Ahmed, S.H. Jhung, J. Hazard. Mat. 301 (2016) 259; (q) C. Pagis, M. Ferbinteanu, G. Rothenberg, S. Tanase, ACS Catal. 6 (2016) 6063; (r) A. Dhakshinamoorthy, A.M. Asiri, H. Garcia, Cat. Sci. Tech. 6 (2016) 5238.

[7] (a) T.C. Johnstone, K. Suntharalingam, S.J. Lippard, Chem. Rev. (2016) 116, 3426; (b) G. Wyszogrodzka, B. Marszałek, B. Gil, P. Dorożyński, Drug Dis. Today 21 (2016) 100; (c) I. Nath, J. Chakraborty, F. Verpoort, Chem. Soc. Rev. 45 (2016) 4127; (d) J. Mehta, N. Bhardwaj, S.K. Bhardwaj, K.H. Kim, A. Deep, Coord. Chem. Rev. 322 (2016) 30; (e) Y. Xia, M.V. Matham, H.B. Su, P. Padmanabhan, B. Gulyas, J. Biomed. Nanotech. 12 (2016) 1553.

[8] Y. Inokuma, T. Arai, M. Fujita, Nature Chem. 2 (2010) 780; Y. Inokuma, S. Yoshioka, J. Ariyoshi, T. Arai, Y. Hitora, K. Takada, S. Matsunaga, K. Rissanen, M. Fujita, Nature 495, 461; M. Hoshino, A. Khutia, H.Z. Xing, Y. Inokuma, M. Fujita, IUCRJ 3 (2016) 139.

[9] G.R. Desiraju, Angew. Chem. Int. Ed. 46 (2007) 8342.

[10] K. Rissanen, CrystEngComm 10 (2008) 1107; G. Kumar, R. Gupta, Chem. Soc. Rev. 42 (2013) 9403; B. Li, S.Q. Zang, L.Y. Wang, T.C.W. Mak, Coord. Chem. Rev. 308 (2016) 1. 
[11] G.R. Desiraju, Angew. Chem. Int. Ed. 34 (1995) 2311.

[12] J.D. Dunitz, A. Gavezzotti, Angew. Chem. Int. Ed. 44 (2005) 1766; J.D. Dunitz, A. Gavezzotti, Cryst. Growth Des. 12 (2012) 5873; G.R. Desiraju, J. Am. Chem. Soc. 135 (2013) 9952; A. Gavezzotti, CrystEngComm 15 (2013) 4027; E.R.T. Tiekink, Chem. Commun. 50 (2014) 11079; A. Gavezzotti, Struct. Chem. 16 (2015) 177; A. Gavezzotti, Israel. J. Chem. DOI: 10.1002/ijch.201600024.

[13] S.L. Price, Chem. Soc. Rev. 43 (2014) 2098.

[14] A.S. Mahadevi, G.N. Sastry, Chem. Rev. 116 (2016) 2775.

[15] M. Etter, Acc. Chem. Res. 23 (1990) 120; J. Bernstein, R.E. Davis, L. Shimont, N.L. Chang, Angew. Chem. Int. Ed. 34 (1995) 1555; T. Steiner, Angew. Chem. Int. Ed. 41 (2002) 48 .

[16] A. Mukherjee, S. Tothadi, G.R. Desiraju, Acc. Chem. Res. 47 (2014) 2514; G. Mínguez Espallargas, F. Zordan, L.A. Marín, H. Adams, K. Shankland, J. van de Streek, L. Brammer, Chem. Eur. J. 15 (2009) 7554; L.C. Gilday, S.W. Robinson, T.A. Barendt, M.J. Langton, B.R. Mullaney, P.D. Beer, Chem. Rev. 115 (2015) 7118; G. Cavallo, P. Metrangolo, R. Milani, T. Pilati, A. Priimagi, G. Resnati, G. Terraneo, Chem. Rev. 166 (2016) 2478.

[17] M.M. Watt, M.S. Collins, D.W. Johnson, Acc. Chem. Res. 46 (2013) 955; M.R. Davies, D.A. Dougherty, Phys. Chem. Chem. Phys. 17 (2015) 29262; N. Busschaert, C. Caltagirone, W. Van Rossom, P.A. Gale, Chem. Rev. 115 (2015) 8038; A. Bauzá, T.J. Mooibroek, A. Frontera, CrystEngComm 18 (2016) 10; M. Giese, M. Albrecht, K. Rissanen, Chem. Commun. 52 (2016) 1778; S. Kozuch, Phys. Chem. Chem. Phys. 18 (2016) 30366.

[18] D. Braga, J. Chem. Soc., Dalton Trans. (2000) p. 3705; L. Brammer, Chem. Soc. Rev. 33 (2004) 476; L. Brammer, G. Mínguez Espallargas, S. Libri, CrystEngComm 10 
(2008) 1712; M.A. Pitt, D.W. Johnson, Chem. Soc. Rev. 36 (2007) 1441; C.B. Aakeröy, N.R. Champness, C. Janiak, CrystEngComm 12 (2010) 22.

[19] (a) K. Brandenburg, DIAMOND. Visual Crystal Structure Information System, version 3.1; Crystal Impact: Bonn, Germany 2006; (b) C.R. Groom, I.J. Bruno, M.P. Lightfoot, S.C. Ward, Acta Cryst. B72 (2016) 171; (c) A.L. Spek, J. Appl. Cryst. 36 (2003) 7.

[20] N.W. Alcock, Adv. Inorg. Chem. Radiochem. 15 (1972) 1; N.W. Alcock, Bonding and Structure: Structural Principles in Inorganic and Organic Chemistry. Ellis Horwood: New York, 1990; P. Pyykkö, Chem. Rev. 97 (1997) 597; I. Haiduc, Coord. Chem. Rev. 158 (1997) 325; J. Starbuck, N.C. Norman, A.G. Orpen, New. J. Chem. 23 (1999) 969; I. Haiduc, in: J.L. Attwood, J.W. Steed (Eds.), Encyclopaedia of Supramolecular Chemistry. Marcel Dekker, New York, 2004, p. 1215, Volume 2.

[21] P. Politzer, J.S. Murray, T. Clark, Phys. Chem. Chem. Phys. 12 (2010) 7748; S. Scheiner, Int. J. Quant. Chem. 113 (2013) 1609; A. Bauzá, T.J. Mooibroek, A. Frontera, ChemPhysChem 16 (2016) 2496; M.H. Kolar, P. Hobza, Chem. Rev. 116 (2016) 5155.

[22] A. Bauzá, T.J. Mooibroek, A. Frontera, Angew. Chem. Int. Ed. 20 (2013) 12317; S.J. Grabowski, Phys. Chem. Chem. Phys. 16 (2014) 1824; G. Mahmoudi, A. Bauzá, A. Frontera, Dalton Trans. 45 (2016) 4965; M. Marin-Luna, I. Alkorta, J. Elguero, J. Phys. Chem. A 120 (2016) 648.

[23] S. Zahn, R. Frank, E. Hey-Hawkins, B. Kirchner, Chem. Eur. J. (2011) p. 6034; S. Scheiner, Acc. Chem. Res. 46 (2013) 280; S.P. Thomas, K. Satheeshkumar, G. Mugesh, T.N. Guru Row, Chem. Eur. J. (2015) p. 6793; S.A. Adonin, M.N. Sokolov, V.P. Fedin, Coord. Chem. Rev. 312 (2016) 1; P.A. Gray, N. Burford, Coord. Chem. Rev. 324 (2016) 1. 
[24] W. Wang, B. Ji, Y. Zhang, J. Phys. Chem. A 113 (2009) 8132; E.R.T. Tiekink, J. Zukerman-Schpector, Coord. Chem. Rev. 254 (2010) 46; A.F. Cozzolino, P.J. Elder, I. Vargas-Baca, Coord. Chem. Rev. 255 (2011) 1426; T. Chivers, R.S. Laitinen, Chem. Soc. Rev. 44 (2015) 1725.

[25] M. Servati Gargari, V. Stilinović, A. Bauzá, A. Frontera, P. McArdle, D. Van Derveer, S.W. Ng, G. Mahmoudi, Chem. Eur. J. (2015) p. 17951.

[26] L. Shimoni-Livny, J.P. Glusker, C.W. Bock, Inorg. Chem. 37 (1998) 1853; R.L. Davidovich, V. Stavila, D.V. Marinin, E.I. Voit, K.H. Whitmire, Coord. Chem. Rev. 253 (2009) 1316; R.L. Davidovich, V. Stavila, K.H. Whitmire, Coord. Chem. Rev. 254 (2010) 2193.

[27] A. Bondi, J. Phys. Chem. 68 (1964) 441.

[28] (a) E.R.T. Tiekink, I. Haiduc, Prog. Inorg. Chem. 54 (2005) 127; (b) M.R. Snow, E.R.T. Tiekink, Aust. J. Chem. 40 (1987) 743; (c) G. Gottardi, Z. Kristallogr. 115 (1961) 451; (d) J.K. Brown, H.D. Arman, P.V. Poplaukhin, E.R.T. Tiekink, Z. Kristallogr. 224 (2009) 368; B.F. Hoskins, E.R.T. Tiekink, G. Winter, Inorg. Chim. Acta 99 (1985) 177.

[29] R.J. Gillespie, Coord. Chem. Rev. 252 (2008) 1315.

[30] (a) K.P. Bhabak, G. Mugesh, Acc. Chem. Res. 43 (2010) 1408; (b) E.R.T. Tiekink, Dalton Trans. 41 (2012) 6390; (c) H.-L. Seng, E.R.T. Tiekink, Appl. Organomet. Chem. 26 (2012) 655; (d) S.P. Thomas, K. Satheeshkumar, G. Mugesh, T.N. Guru Row, Chem. Eur. J. (2015) p. 6793.

[31] H.-B. Bürgi, J.D. Dunitz, Helv. Chim. Acta 76 (1993) 1115.

[32] (a) M.M. Jotani, Y.S. Tan, E.R.T. Tiekink, Z. Kristallogr. 231 (2016) 403; (b) E.R.T. Tiekink, CrystEngComm 5 (2003) 101; (c) E.R.T. Tiekink, CrystEngComm, 8 (2006) 104. 
[33] (a) M.J. Cox, E.R.T. Tiekink, Main Group Met. Chem. 23 (2000) 793; (b) M.J. Cox, E.R.T. Tiekink, Z. Kristallogr. 214 (1999) 571; (c) P.C. Healy, A.H. White, J. Chem. Soc., Dalton Trans. (1973) p. 284; (d) C.S. Lai, E.R.T. Tiekink, Z. Kristallogr. - New Cryst. Struct. 217 (2002) 593; (e) N. Srinivasan, S. Thirumaran, S. Ciattini, RSC Adv. 4 (2014) 22971.

[34] M.J. Katz, K. Sakai, D.B. Leznoff, Chem. Soc. Rev. 37 (2008) 1884.

[35] P. Pyykkö, Angew. Chem. Int. Ed. 43 (2004) 4412; S. Sculfort, P. Braunstein, Chem. Soc. Rev. 40 (2011) 2741; P. Pyykkö, in M.A. Johnsonm T.J. Martinez (Eds.), Ann. Rev. Phys. Chem. 63 (2012) 45.

[36] F. Scherbaum, A. Grohmann, B. Huber, C. Krüger, H. Schmidbaur, Angew. Chem., Int. Ed. Engl. 27 (1988) 1544.

[37] D.D. Heinrich, J.-C. Wang, J.P. Fackler Jr, Acta Crystallogr. C46 (1990) 1444; D. Paliwoda, P. Wawrzyniak, A. Katrusiak, J. Phys. Chem. Lett. 5 (2014) 2182.

[38] F.S. Kuan, S.Y. Ho, P.P. Tadbuppa, E.R.T. Tiekink, CrystEngComm 10 (2008) 548.

[39] A.E. O’Connor, N. Mirzadeh, S.K. Bhargava, T.L. Easun, M. Schröder, A.J. Blake, Chem. Commun. 52 (2016) 6769.

[40] H. Schmidbaur, A. Schier, Chem. Soc. Rev. 37 (2008) 1931; H.E. Abdou, A.A. Mohamed, J.P. Fackler, A. Burini, R. Galassi, J.M. Lopez-de-Luzuriaga, M.E. Olmos, Coord. Chem. Rev. 253 (2009) 1661; H. Schmidbaur, A. Schier, Chem. Soc. Rev. 41 (2012) 370.

[41] H. Schmidbaur, K. Dziwok, A. Grohmann, G. Müller, Chem. Ber. 122 (1989) 893; H. Schmidbaur, A. Schier, Gold Bull. 33 (2000) 3; H. Schmidbaur, Nature 413 (2001) 31.

[42] (a) W. Schneider, A. Bauer, H. Schmidbaur, Organometallics 15 (1996) 5445; (b) A. Codina, E.J. Fernandez, P.G. Jones, A. Laguna, J.M. Lopez-de-Luzuriaga, M. Monge, 
M.E. Olmos, J. Perez, M.A. Rodriguez, J. Am. Chem. Soc. 124 (2002) 6781; (c) W.J. Hunks, M.C. Jennings, R.J. Puddephatt, Inorg. Chem. 41 (2002) 4590; (d) E.R.T. Tiekink, Coord. Chem. Rev. 275 (2014) 130.

[43] M.B. Smith, S.H. Dale, S.J. Coles, T. Gelbrich, M.B. Hursthouse, M.E. Light, CrystEngComm 8 (2006) 140.

[44] U. Helmstedt, S. Lebedkin, T. Hocher, S. Blaurock, E. Hey-Hawkins, Inorg. Chem. 47 (2008) 5815.

[45] E.R.T. Tiekink, J.-G. Kang, Coord. Chem. Rev. 253 (2009) 1627; J.C. Lima, L. Rodriguez, Chem. Soc. Rev. 40 (2011) 5442.

[46] (a) X. He, V.W.-W. Yam, Coord. Chem. Rev. 255 (2011) 2111; (b) X.-X. Lu, C.-K. Li, E.C.-C. Cheng, N. Zhu, V.W.-W. Yam, Inorg. Chem. 43 (2004) 2225.

[47] (a) C. Jobbágy, A. Deák, Eur. J. Inorg. Chem. (2014) p. 4434; (b) H. Ito, M. Muromoto, S. Kurenuma, S. Ishizaka, N. Kitamura, H. Sato, T. Seki, Nat. Commun. 4 (2013) 2009.

[48] W. Lu, K.T. Chan, S.-X. Wu, Y. Chen, C.-M. Che, Chem. Sci. 3 (2012) 752.

[49] A. Aliprandi, D. Genovese, M. Mauro, L. De Cola, Chem. Lett. 44 (2015) 1152; B.M. Anderson, S.K. Hurst, Eur. J. Inorg. Chem. (2009) p. 3041.

[50] H. Schmidbaur, A. Schier, Organometallics 34 (2015) 20148.

[51] M. Krikorian, S. Liu, T.M. Swager, J. Am. Chem. Soc. 136 (2014) 2952.

[52] J. Bravo, J.S. Casas, Y.P. Mascarenhas, A. Sánchez, C. de O.P. Santos, J. Sordo, Chem. Commun. (1986) p. 1100.

[53] H. Schmidbaur, A. Schier, Angew. Chem. Int. Ed. 54 (2015) 746.

[54] (a) R. Medishetty, I.H. Park, S.S. Lee, J.J. Vittal, Chem. Commun. 52 (2016) 3989; (b) L.R. Macgillivray, G.S. Papaefstathiou, T. Friščić, T.D. Hamilton, D.K. Bučar, Q. Chu, D.B. Varshney, I.G. Georgiev, Acc. Chem. Res. 41 (2008) 280. 
[55] Q.L. Chu, D.C. Swenson, L.R. MacGillivray, Angew. Chem. Int. Ed. 44 (2005) 3569.

[56] (a) R. Donamaría, M.C. Gimeno, V. Lippolis, J.M. López-de-Luzuriaga, M. Monge, M.E. Olmos, Inorg. Chem. 55 (2016) 11299; (b) V. Vreshch, W.T. Shen, B. Nohra, S.K. Yip, V.W.W. Yam, C. Lescop, R. Reau, Chem. Eur. J. (2012) p. 466.

[57] (a) R. Echeverría, J.M. López-de-Luzuriaga, M. Monge, S. Moreno, M.E. Olmos, Inorg. Chem. 55 (2016) 10523; (b) R. Echeverría, J.M. López-De-Luzuriaga, M. Monge, M.E. Olmos, Chem. Sci. 6 (2015) 2022.

[58] J.D. Dunitz, R. Taylor, Chem.-Eur. J. 3 (1997) 89.

[59] (a) S. Trofimenko, J. Am. Chem. Soc. 90 (1968) 4754; (b) W.I. Sundquist, D.P. Bancroft, S.J. Lippard, J. Am. Chem. Soc. 112 (1990) 1590; (c) L. Brammer, Dalton Trans. (2007) p. 3145; (d) M. Brookhart, M.L.H. Green, G. Parkin, Proc. Acad. Sci. U.S.A. 104 (2007) 6908; (e) J. Saßmannhausen, Dalton Trans, 41 (2012) 1919; W. Scherer, A.C. Dunbar, J.E. Barquera-Lozada, D. Schmitz, G. Eickerling, D. Kratzert, D. Stalke, A. Lanza, P. Macchi, N.P.M. Casati, J. Ebad-Allah, C. Kuntscher, Angew. Chem. Int. Ed. 54 (2015) 2505.

[60] (a) M. Baya, U. Belio, A. Martin, Inorg. Chem. 53 (2014) 189; (b) H. Schmidbaur, H.G. Raubenheimer, L. Dobrzańska, Chem. Soc. Rev. 43 (2014) 345.

[61] S. Rizzato, J. Bergès, S.A. Mason, A. Albinati, J. Kozelka, Angew. Chem. Int. Ed. 49 (2010) 7440.

[62] (a) S.K. Singh, M.G.B. Drew, N. Singh, CrystEngComm 15 (2013) 10255; (b) A.N. Gupta, V. Kumar, V. Singh, K.K. Manar, M.G.B. Drew, N. Singh, CrystEngComm 16 (2014) 9299; (c) M.K. Yadav, G. Rajput, L.B. Prasad, M.G.B. Drew, N. Singh, New J. Chem. 39 (2015) 5493.

[63] (a) K.A. Siddiqui, E.R.T. Tiekink, Chem. Commun. 49 (2013) 8501; (b) M.A. Siegler, M. Lutz, Cryst. Growth Des. 9 (2009) 1194; (c) F.D. Lesh, S.S. Hindo, M.J. Heeg, 
M.M. Allard, P. Jain, B. Peng, L. Hryhorczuk, C.V. Verani, Eur. J. Inorg. Chem. (2009) p. 345; (d) S. Gambarotta, M. Bracci, C. Florini, A. Chiesi-Villa, C. Guastini, J. Chem. Soc., Dalton Trans. (1987) p. 1883.

[64] (a) E.A. Meyer, R.K. Castellano, F. Diederich, Angew. Chem. Int. Ed. 42 (2003) 1210; (b) O. Takahashi, Y. Kohno, M. Nishio, Chem. Rev. 110 (2010) 6049; (c) M. Nishio, Y. Umezawa, J. Fantini, M.S. Weiss, P. Chakrabarti, Phys. Chem. Chem. Phys. 16 (2014) 12648 (d) C. Janiak, J. Chem. Soc., Dalton Trans. (2000) p. 3885.

[65] A. Frontera, P. Gamez, M. Mascal, T.J. Mooibroek, J. Reedijk, Angew. Chem. Int. Ed. 41 (2011) 9564; K.D. Daze, F. Hof, Acc. Chem. Res. 46 (2013) 937; H.J. Schneider, Acc. Chem. Res. 46 (2013) 1010.

[66] H.T. Chifotides, K.R. Dunbar, Acc. Chem. Res. 46 (2013) 894; N.H. Evans, P.D. Beer, Angew. Chem. Int. Ed. 53 (2014) 11716; M. Giese, M. Albrecht, K. Rissanen, Chem. Rev. 115 (2015) 8867; M.T. Rodgers, P.B. Armentrout, Chem. Rev. 116 (2016) 5642.

[67] D.A. Dougherty, Science 271 (1996) 163; J.C. Ma, D.A. Dougherty, Chem. Rev. 97 (1997) 1303.

[68] (a) H. Schmidbaur, A. Schier, Organometallics 29 (2010) 2; (b) M. Haruta, Gold Bull. 37 (2004) 27; (c) N. Krause, C. Winter, Chem. Rev. 111 (2011) 1994; (d) M. Rudolph, A.S.K. Hashmi, Chem. Soc. Rev. 41 (2012) 2448; (e) R. Ciriminna, E. Falletta, C. Della Pina, J.H. Teles, M. Pagliaro, Angew. Chem. Int. Ed. 55 (2016) 14209.

[69] (a) H. Schmidbaur, A. Wohlleben, F. Wagner, O. Orama, G. Huttner, Chem. Ber. 110 (1977) 1748; (b) P.C. Healy, Acta Crystallogr. E 59 (2003) m1112.

[70] C.I. Yeo, C.-H. Khoo, W.-C. Chu, B.-J. Chen, P.-L. Chu, J.-H. Sim, Y.-K. Cheah, J. Ahmad, S.N.A. Halim, H.-L. Seng, S. Ng, A. Otero-de-la-Roza, E.R.T. Tiekink, RSC 
Adv. 5 (2015) 41401; C.-I. Yeo, S.L. Tan, A. Otero-de-la-Roza, E.R.T. Tiekink, Z. Kristallogr. 231 (2016) 653.

[71] E.R.T. Tiekink, J. Zukerman-Schpector, CrystEngComm 11 (2009) 1176; E.R.T. Tiekink, J. Zukerman-Schpector, CrystEngComm 11 (2009) 2701; I. Caracelli, J. Zukerman-Schpector, E.R.T. Tiekink, Gold Bull. 46 (2013) 81.

[72] D. Schollmeyer, O.V. Shishkin, T. Rühl, M.O. Vysotsky, CrystEngComm 10 (2008) 715; O.V. Shishkin, Chem. Phys. Lett. 458 (2008) 96.

[73] (a) P. Lange, A. Schier, H. Schmidbaur, Inorg. Chem. 35 (1996) 637, (b) J. Mack, K. Ortner, U. Abram, R.V. Parish, Z. Anorg. Allg. Chem. 623 (1997) 873; (c) B. Weissbart, L.J. Larson, M.M. Olmstead, C.P. Nash, D.S. Tinti, Inorg. Chem. 34 (1995) 393.

[74] H. Schmidbaur, A. Schier, Organometallics 27 (2008) 2361.

[75] M. Egli, S. Sarkhel, Acc. Chem. Res. 40 (2007) 197.

[76] J. Zukerman-Schpector, I. Haiduc, CrystEngComm 4 (2002) 178.

[77] (a) I. Haiduc, E.R.T. Tiekink, J. Zukerman-Schpector, in: A.G. Davies, M. Gielen, K.H. Pannell, E.R.T. Tiekink (Eds.), Tin Chemistry Fundamentals, Frontiers and Applications, John Wiley \& Sons Ltd, Chichester, 2008, p. 392, Chapter 3.9; (b) E.R.T. Tiekink, J. Zukerman-Schpector, Aust. J. Chem. 63 (2010) 535; (c) I. Caracelli, I. Haiduc, J. Zukerman-Schpector, E.R.T. Tiekink, Coord. Chem. Rev. 281 (2014) 50; (d) J. Zukerman-Schpector, A. Otero-dela-Roza, V. Luaña, E.R.T. Tiekink, Chem. Commun. 47 (2011) 7608; (e) I. Caracelli, I. Haiduc, J. Zukerman-Schpector, E.R.T. Tiekink, Coord. Chem. Rev. 257 (2013) 2863; (f) I. Caracelli, J. Zukerman-Schpector, E.R.T. Tiekink, Coord. Chem. Rev. 256 (2012) 412; (g) I. Caracell, I. Haiduc, J. Zukerman-Schpector, E.R.T. Tiekink, in: Z. Rappoport (Ed.), The Chemistry of Organic Selenium and Tellurium Compounds, John Wiley \& Sons Ltd, Chichester, 
2013, vol. 4, p. 973, Chapter 12; (h) E.R.T. Tiekink, J. Zukerman-Schpector, CrystEngComm 11 (2009) 2701; (i) I. Haiduc, E.R.T. Tiekink, J. Zukerman-Schpector, in: E.R.T. Tiekink, J. Zukerman-Schpector (Eds), The Importance of Pi-Interactions in Crystal Engineering, John Wiley \& Sons Ltd, Chichester, 2012, p. 301, Chapter 11; (j) I. Caracelli, I. Haiduc, J. Zukerman-Schpector, E.R.T. Tiekink, in: D.W. Johnson, F. Hof (Eds), Aromatic Interactions: Frontiers in Knowledge and Application, Royal Society of Chemistry, Abingdon, 2016, p. 98, Chapter 4; (k) I. Caracelli, J. ZukermanSchpector, I. Haiduc, E.R.T. Tiekink, CrystEngComm 18 (2016) 6960.

[78] (a) G.P.A. Yap, F. Jove, J. Urbano, E. Alvarez, S. Trofimenko, M.M. Diaz-Requejo, P.J. Perez, Inorg. Chem. 46 (2007) 780; (b) A. Akkari, J.J. Byrne, I. Saur, G. Rima, H. Gornitzka, J. Barrau, J. Organomet. Chem. 622 (2001) 190; (c) T. Probst, O. Steigelmann, J. Riede, H. Schmidbaur, Chem. Ber. 124 (1991) 1089; (d) N. Burford, J.A.C. Clyburne, J.A. Wiles, T.S. Cameron, K.N. Robertson, Organometallics 15 (1996) 361 .

[79] (a) J.M. Kisenyi, G.R. Willey, M.G.B. Drew, S.O. Wandiga, J. Chem. Soc., Dalton Trans. (1985) p. 69; (b) M. Mehring, M. Schurmann, Chem. Commun. (2001) p. 2354; (c) G. Le Guillanton, A.V. Martynov, J. Delaunay, N. Mercier, A. Riou, J. Chem. Res. (S) (1998) p. 681.

[80] M. Sato, Y. Kanatomi, J. Sulfur Chem. 30 (2009) 469.

[81] (a) R. Lo, P. Švec, Z. Růžíčková, A. Růžíčka, P. Hobza, Chem. Commun. 52 (2016) 3500; M. Saberinasab, S. Salehzadeh, Y. Maghsoud, M. Bayat, Comp. Theoret. Chem. 1078 (2016) 9; R.W. Newberry, S.J. Orke, R.T. Raines, Org. Lett. 18 (2016) 3614.

[82] H. Masui, Coord. Chem. Rev. 219-221 (2001) 957.

[83] M.K. Milčić, B.D. Ostojić, S.D. Zarić, Inorg. Chem. 46 (2007) 7109; E. Kleinpeter, A. Koch, Phys. Chem. Chem. Phys. 13 (2011) 20593; S.E. Wheeler, Acc. Chem. Res. 46 
(2013) 1029; R. Islas, J. Poater, M. Solà, Organometallics 33 (2014) 1762; J.J. TorresVega, A. Vásquez-Espinal, J. Caballero, M.L. Valenzuela, L. Alvarez-Thon, E. Osorio, W. Tiznado, Inorg. Chem. 53 (2014) 3579.

[84] (a) Z.D. Tomić, D. Sredojević, S.D. Zarić, Cryst. Growth Des. 6 (2006) 29; (b) D. Sredojević, D.Z. Vojislavljević, Z.D. Tomić, S.D. Zarić, Acta Crystallogr. B68 (2012) 261.

[85] A.N. Gupta, V. Kumar, V. Singh, K.K. Manar, A.K. Singh, M.G.B. Drew, N. Singh, Polyhedron 101 (2015) 251.

[86] (a) D. Sredojević, Z.D. Tomić, S.D. Zarić, Cryst. Growth Des. 10 (2010) 3901; (b) D.P. Malenov, G.V. Janjić, V.B. Medaković, M.B. Hall, S.D. Zarić, Coord. Chem. Rev. in press.

[87] (a) J. Kožíšek, M. Hvastijová, J. Kohout, Inorg. Chim. Acta 168 (1990) 157; (b) R. Boča, M. Hvastijová, J. Kozisek, M. Valko, Inorg. Chem. 35 (1996) 4794; (c) M.-L. Tong, Y.-M. Wu, Y.-X. Tong, X.-M. Chen, H.-C. Chang, S. Kitagawa, Eur. J. Inorg. Chem. (2003) p. 2385; (d) S. Jana, S. Khan, A. Bauzá, A. Frontera, J. Mol. Struct. 1127 (2017) 355 .

[88] D. Sredojević, G.A. Bogdanović, Z.D. Tomić, S.D. Zarić, CrystEngComm 9 (2007) 793.

[89] (a) D. Chen, C.S. Lai, E.R.T. Tiekink, Z. Kristallogr. 218 (2003) 747; (b) E.R.T. Tiekink, J. Zukerman-Schpector, Chem. Commun. 47 (2011) 6623; (c) A.N. Gupta, V. Kumar, V. Singh, K.K. Manar, M.G.B. Drew, N. Singh, CrystEngComm 16 (2014) 9299; (d) Y.S. Tan, S.N.A. Halim, K.C. Molloy, A.L. Sudlow, A. Otero-de-la-Roza, E.R.T. Tiekink, CrystEngComm 18 (2016) 1105; (e) E. Sathiyaraj, P. Selvaganapathi, S. Thirumaran, S. Ciattini, J. Molec. Struct. 1119 (2016) 385. 
[90] (a) M.K. Milčič, V.B. Medaković, D.N. Sredojević, N.O. Juranić, Z.D. Tomić, S.D. Zarić, Inorg. Chem. 45 (2006) 4755; (b) N.K. Shee, D. Datta, Inorg. Chim. Acta 453 (2016) 339; (c) V.B. Medaković, G.A. Bogdanović, M.K. Milčič, G.V. Juranić, S.D. Zarić, J. Inorg. Biochem. 117 (2012) 157; (d) Y.-F. Jiang, C.-J. Xi, Y.-Z. Liu, J. Niclós-Gutiérrez, D. Choquesillo-Lazarte, Eur. J. Inorg. Chem. 2005, p. 1585.

[91] A.N. Knyazeva, E.A. Shugam, L.M. Shkol'nikova, Zh. Strukt. Khim. 11 (1970) 938; M. Hamid, M. Zeller, A.D. Hunter, M. Mazhar, A.A. Tahir, Acta Crystallogr. E61 (2005) m2181.

[92] H. Karabıyık, H. Karabıyı, N.O. Îskeleli, Acta Crystallogr. B68 (2012) 71; H. Karabıyık, R. Sevincek, H. Karabıyık, J. Molec. Struct. 1064 (2014) 135; M.P. RomeroFernández, M. Ávalos, R. Babiano, P. Cintas, J.L. Jiménez, J.C. Palacios, J. Phys. Chem. A 119 (2015) 525.

[93] J.P. Blagojević, S.D. Zarić, Chem. Commun. 51 (2015) 12989.

[94] (a) C.I. Yeo, S.N.A. Halim, S.W. Ng, S.L. Tan, J. Zukerman-Schpector, M.A.B. Ferreira, E.R.T. Tiekink, Chem. Commun. 50 (2014) 5984; (b) J. ZukermanSchpector, C.I. Yeo, E.R.T. Tiekink, Z. Kristallogr. 231 (2016) 55.

[95] (a) S. Ramaprabhu, E.A.C. Lucken, G. Bernardinelli, J. Chem. Soc., Dalton Trans. (1995) 115; (b) T.S. Lobana, R. Sharma, R. Sharma, R.J. Butcher, Z. Anorg. Allg. Chem. 634 (2008) 1785.

[96] F.H. Allen, W.D.S. Motherwell, P.R. Raithby, G.P. Shields, R. Taylor, New. J. Chem. (1999) p. 25. 